Digitized by the Internet Archive in 2011 with funding from University of Illinois Urbana-Champaign 


\section{Toxicity of Ingested Bismuth Alloy Shot in Game-farm Mallards}

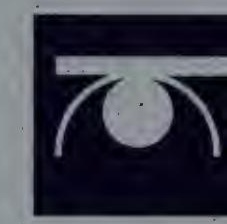

Glen C. Sanderson, William L. Anderson, George L.. Foley, Loretta M. Skowron, Jeffrey D. Brawn, James W. Seets, and Karen L. Duncan

Illinois Natural History Survey Bulletin

Volume 35, Articles 3 and 4 .

April 1997 
Illinois Natural. History Survey, Edward J. Armbrust, Acting:Chief A Division of the Illinois Department of Natural Resources

A catalog of the publications of the Illinois Natural History Survey is available without charge from the address below. A price list and an order blank are included with the catalog.

Illinois Natural History Survey

Distribution Center

Natural Resources Building.

607 East Peabody Drive

Champaign, Illinois 61820

\section{Citations:}

Sanderson, G.C., W.L. Anderson, G.L. Foley, L.M. Skowron, J.D. Brawn, and J.W. Seets. 1997. Acute toxicity of ingested bismuth alloy shot in game-farm mallards. Illinois Natural History Survey Bulletin 35(3): 185-216.

Sanderson, G.C., W.L: Anderson, G.L. Foley, K.L. Duncan, L.M. Skọwron, J.D. Brawn, and J.W. Seets. 1997. Toxicity of ingested bismuth alloy shot in game-farm mallards: chronic health effects and effects on reproduction. Illinois Natural History Survey Bulletin 35(4):217-252.

Editors: Thomás E. Rice and Charles Warwick

US ISSN 0073-4918

Printed by Authority of the State of Illinois

(MJ412759-1 M-4-97)

Printed with soy ink on recycled and recyclable paper.

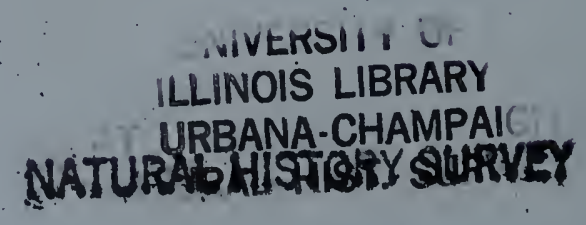




\section{Contents}

Article 3: Acute Toxicity of Ingested Bismuth Alloy Shot in Game-farm Mallards

Acknowledgments ii

Abstract 185

INTRODUCTION 185

Literature Review 185

Methods 187

Toxicity Study 187

Chemical Analyses 189

Storage of Samples 189

Digestions of Samples 189

Digestions for ICP Analysis 189

Digestions for GFAA Analysis 189

Analytical Methods 189

ICP 189

GFAA 190

Quality Control 190

Calculations 190

Statistical Analyses 190

Results 191

Survival 191

Retention and Dissolution of Shot 191

Body Weight 192

Organ Weights 192

Gizzard 192

Liver 192

Kidneys 192

Gonads 192

Hematocrit (Hct) 192

Heavy Metals and Essential Elements in Organs and Blood 192

Kidneys 195

Liver 195

Gonads 202

Plasma and Blood Cells 204

Feces 208

Histopathology 208

Gonadal Lesions 208

Female 208

Male 208

Liver 211

Kidneys 211

Gizzard 211

Discussion 212

Copper 212

Phosphorous 212

Iron 212

Calcium 212

Feces 212

Conclusions 213

Literature Cited 214 
Article 4: Toxicity of Ingested Bismuth Alloy Shot in Game-farm Mallards: Chronic Health Effects and Effects on Reproduction Acknowledgments ii

Abstract 217

INTRODUCTION 217

Methods 217

Toxicity Sudy 217

Chemical Analyses 220

Storage of Samples 220

Digestions of Samples 220

Digestions for ICP Analysis 220

Digestions for GFAA Analysis 221

Analytical Methods 221

ICP 221

GFAA 221

Quality Control 221

Calculations 221

Statistical Analyses 222

Results 222

Chronic Toxicity Test 222

Survival 222

Hematocrit 222

Body Weight 222

Dissolution of Shot 222

Shot Retention 226

Organ Weights 228

Analyses of Tissues and Other Materials 231

Kidneys 231

Liver 231

Gonads 234

Blood 236

Reproduction 236

Eggs 236

Ducklings 240

Egg Weights 244

Egg Shell Thickness 244

Fertility Rates 244

Hatchability Rates 244

Egg Shell Analysis 244

Egg Content Analysis 244

Age of Embryo at Time of Death 247

Histopathology 247

Adults 247

Kidneys 247

Liver 247

Gonads 248

Heart 248

Lungs 248

Ducklings 248

Liver 248

Kidneys 248

Discussion 248

Heart 248

Conclusions 250

Literature Cited 251 




\section{ILLINOIS \\ NATURAL \\ HISTORY \\ S UR VEY}

\section{Acute Toxicity of Ingested Bismuth Alloy Shot in Game-farm Mallards}

Glen C. Sanderson

Illinois Natural History Survey

William L. Anderson

Illinois Department of Natural Resources and

Illinois Natural History Survey

George L. Foley

University of Illinois and

Illinois Natural History Survey

Loretta M. Skowron

Illinois State Water Survey

Jeffrey D. Brawn

Illinois Natural History Survey

James W. Seets

Illinois Natural History Survey

Illinois Natural History Survey Bulletir

Volume 35, Article 3

April 1997 


\section{Acknowledgments}

James W. Sergent and Wendy L. Grethen, Illinois Natural History Survey, fed the ducks, cleaned the pens, examined the feces for voided shot, saved fecal samples for chemical analysis, and assisted with other phases of the study. The following people assisted with weighing and dosing ducks and collecting and processing blood: Stephen P. Havera, Michelle M. Georgi, Aaron P. Yetter, and Christopher S. Hine, all with the Waterfowl Research Laboratory, Forbes Biological Station, Illinois Natural History Survey, Havana, Illinois; Edward J. Heske, Linda K. Campbell, and Anne E. Zielske, all with the Illinois Natural History Survey; and volunteers Beverley C. Sanderson and J. William Sanderson. Beverley C. Sanderson also assisted with many tasks in the preparation of this manuscript. William R. Manuel, retired, College of Veterinary Medicine, University of Illinois, provided his expertise in the collection of blood. We thank Jerry L. Longcore, Leader, Patuxent Wildlife Research Center, Orono, Maine; Lawrence J. Blus, Wildlife Research Biologist, Biological Resources Division, U.S. Geological Survey; and Louis N. Locke, Wildlife Pathologist, and Milton Smith, Chemist, National Wildlife Health Center, for their reviews of the manuscript. Petersen Publishing Company, Los Angeles, California, provided financial support for the research and costs of this publication. 


\section{Abstract}

In a 30-day study involving penned game-farm mallards (Anas platyrhynchos), no harmful health effects were detected from dosing with either six, No. 4, bismuth/tin (Bi/Sn) alloy shot or six, No. 4, steel (Fe) shot, as compared with sham (0 shot) dosing. Survival, hematocrit (Hct) values, body weight, and mean weights of kidneys, livers, gonads, and gizzards were not affected. Mean concentrations of nutritionally essential elements (calcium [Ca], phosphorous [P], magnesium [Mg], zinc [Zn], copper $[\mathrm{Cu}], \mathrm{Fe}$, and $\mathrm{Sn}$ ) were different among doses and between sexes in kidneys, livers, and gonads. However, concentrations of these elements in these organs and tissues in Bi-dosed ducks were not different from both 0 - and Fe-dosed ducks. Bi/Sn alloy shot, as tested in this study, elicited no indications of toxicity in game-farm mallard ducks.

\section{Introduction}

To protect waterfowl from poisoning caused by ingested lead $(\mathrm{Pb})$ shot, nontoxic shot regulations were implemented for waterfowl hunting on areas with severe problems with $\mathrm{Pb}$ poisoning ("hotspots") in the United States beginning in the early 1970s (Anderson 1992). Federal regulations became nationwide in 1991. Several European countries have converted or are planning to convert to nontoxic shot for waterfowl hunting (Moser 1992) and Canada will implement a nationwide ban on lead shot for all migratory bird hunting in 1997 (Canadian Wildlife Service [CWS] 1995). From the 1970s to the early 1990s, Fe was the only shot material approved as nontoxic by the U.S. Fish and Wildlife Service (USFWS) (Longcore et al. 1974). Although hunters have generally adapted to using Fe shot, some have urged that a search for alternative shot with greater ballistic capability be continued. Specifically, they wanted a shot that is nontoxic, inexpensive, and ballistically similar to lead shot. There have been numerous evaluations of potential substitute shot. Irby et al. (1967) evaluated three types of plastic-coated $\mathrm{Pb}$, two $\mathrm{Pb} / \mathrm{Mg}$ alloys, $\mathrm{Fe}, \mathrm{Cu}, \mathrm{Zn}$-coated $\mathrm{Fe}$, and molybdenum-coated Fe. Longcore et al. (1974) evaluated $\mathrm{Pb}$ shot with nickel coatings, $\mathrm{Pb} /$ phosphor $\mathrm{Sn}$ alloy shot, $\mathrm{Pb}$ shot with $\mathrm{Sn} /$ nickel alloy coatings, steel shot with $\mathrm{Pb}$ coatings, $\mathrm{Pb} / \mathrm{Sn}$ alloys, two types of disintegrable $\mathrm{Pb}$ shot, and $\mathrm{Pb}$ shot with biochemical additives. Haseltine and Sileo (1983) evaluated uranium. No satisfactory alternative was found until 1990, when John E. Brown, St. Catherines, Ontario, was awarded a U.S. patent for Bi shot.

Our primary objective was to determine if $\mathrm{Bi} / \mathrm{Sn}$ alloy shot caused toxic effects in captive game-farm mallards. Secondly, if toxic effects were manifest, we wanted to associate toxic effects with amounts of $\mathrm{Bi}$ and other elements in the tissues. Our study complied with the "Acute Toxicity Test" guidelines of the USFWS and the CWS. Dr. Simon Nadeau, CWS, and Dr. Keith A. Morehouse, USFWS, reviewed our protocol before we initiated our study.

\section{Literature Review}

The first known report of metallic Bi dosed in birds was by Hanzlik and Presho (1923), who administered metallic $\mathrm{Bi}, \mathrm{Pb}$, and other heavy metals to pigeons. The fatal dose of metallic $\mathrm{Pb}$ in their studies ranged from 0.6 to $2.28 \mathrm{~g} / \mathrm{kg}$. By contrast, none of the four Bi-dosed pigeons died after receiving doses that averaged $1.39 \mathrm{~g} / \mathrm{kg}$, and the researchers concluded that $\mathrm{Pb}$ is more toxicand mortality is higher with smaller doses-than other heavy metals, including $\mathrm{Bi}$. Sanderson et al. (1992) conducted the first comprehensive study to determine the toxicity of ingested Bi shot $(100 \%$ Bi) in birds (mallards). They followed with tests on ingested $\mathrm{Bi} / \mathrm{Sn}$ alloy shot (Sanderson et al. 1997b) and the present study. Sanderson et al. (1997b) reported that reproduction of game-farm mallards was not affected after chronic dosing with Bi/Sn alloy shot. Sanderson et al. (1997a) reported no toxic effects of $\mathrm{Bi}$ shot embedded in the breast muscles of game-farm mallards.

The International Commission on Radiological Protection (ICRP) (1960) reported that $\mathrm{Bi}$ is rapidly excreted by the kidneys except for small amounts retained in these organs. Some $\mathrm{Bi}$ is lost in bile. The estimated half-time for elimination in humans was about 5 days. Hamilton et al. (1972/ 1973) reported $0.4 \mu \mathrm{g} / \mathrm{g}$ Bi (wet weight) in kidneys and $0.004 \mu \mathrm{g} / \mathrm{g}$ Bi in livers of autopsy cases (humans) with no known exposure to Bi. Kidneys of 22 individuals who had been given $B i$ salicylate had $33 \mu \mathrm{g} / \mathrm{g}$ Bi and livers had $6.8 \mu \mathrm{g} / \mathrm{g} B i$. 
Lee (1981) reported that after treatment was terminated, Bi declined about $2.6 \%$ in the urine daily, with half purged from the body in about 20 days. Fowler and Vouk (1979:348) stated, "Ingested bismuth is largely eliminated unabsorbed in feces. Model values for the daily balance of bismuth in reference man are: dietary intake 20 $\mu \mathrm{g} / \mathrm{g}$, fecal elimination $18 \mu \mathrm{g} / \mathrm{g}$, urinary excretion $1.6 \mu \mathrm{g} / \mathrm{g} . .$. Absorbed bismuth is mainly excreted in the urine."

Oehme (1979) reported that soluble and insoluble Bi salts, suspended in oil to maintain levels in blood, were injected to treat syphilis. Other Bi compounds were used to treat malaria and amebiasis. Medicinal use of Bi decreased with the advent of newer treatments. Most human exposure to $\mathrm{Bi}$ is in compounds that are insoluble and not readily absorbed whether ingested or applied to the skin. Apparently tissue binding is slight, even when $\mathrm{Bi}$ is absorbed. An equilibrium is established among tissues, blood, and urine. Kidneys have the highest amounts of $\mathrm{Bi}$, with the liver generally a poor second. With few exceptions, Bi compounds present no problems whether by ingestion, inhalation, or dermal application. Poisoning from industrial exposure is rare (Oehme 1979).

There are no federal standards for Bi or its compounds and no evidence linking $\mathrm{Bi}$ or $\mathrm{Bi}$ compounds with industrial poisoning. Also, all episodes of $\mathrm{Bi}$ poisoning were from soluble compounds used in medicine, and fatalities and near fatalities were mainly from intravenous or intramuscular injection of soluble salts (Key et al. 1977). Venugopal and Lukey (1978) reported that low solubility limits the toxicity of Bi compounds, which are highly toxic. Locke et al. (1987) reported neurotoxic effects at Bi concentrations of $<0.1 \mu \mathrm{g} / \mathrm{g}$ in blood.

Thomas et al. (1988:124) reported, "Since toxicity resulting from environmental or industrial exposure to bismuth or any of its compounds is not a problem, levels of tolerance have not been identified ...." Bi telluride, which is used as a semiconductor in the electronics industry (Oehme 1979), is an exception. Thomas et al. (1988) reported, however, that the French Ministry of Health banned the sale and use of all Bi compounds, and that Australia restricted the use of $\mathrm{Bi}$ subgallate. These authors suggested that in humans amounts of $\mathrm{Bi}$ in blood $>0.48 \mu \mathrm{mol} / \mathrm{L}(0.1$ $\mu \mathrm{g} / \mathrm{mL}$ ) are potentially dangerous, that amounts $>0.05$ and $<0.1 \mu \mathrm{g} / \mathrm{mL}$ call for careful monitoring of patients, and that amounts $<0.05 \mu \mathrm{g} / \mathrm{mL}$ are considered safe.
Krigman et al. (1985) reported that levels of Bi in blood of humans differ between individuals who show side effects from chronic use of $\mathrm{Bi}$ and those who do not. Those who show no effects usually have $<0.05 \mu \mathrm{g} / \mathrm{g} \mathrm{Bi}$ in their blood whereas those who show symptoms have $>0.05 \mu \mathrm{g} / \mathrm{g} \mathrm{Bi}$ in their blood. These authors conclude that levels of $\mathrm{Bi}$ in blood $>0.05 \mu \mathrm{g} / \mathrm{g}$ indicate a high risk and amounts $<0.05 \mu \mathrm{g} / \mathrm{g}$ indicate a low risk. Other investigators (Hillemond et al. 1977; Serfontein and Mekel 1979) concluded that $0.05 \mu \mathrm{g} / \mathrm{g} \mathrm{Bi}$ in blood is potentially neurotoxic. Dipalma (1988) stated that levels of $\mathrm{Bi}$ in blood should not be $>0.02 \mu \mathrm{g} / \mathrm{g}$.

Dipalma (1988) reported that exposure of humans to $\mathrm{Bi}$ is not considered a serious industrial hazard. According to him, there are few data on Bi concentrations in blood from either oral or topical applications because of the assumption that absorption of $\mathrm{Bi}$ is low. Dipalma (1988) indicated that bacteria in the intestine might methylate Bi to form a soluble compound. He reported (p. 244), "In animals, trimethyl bismuth is highly toxic and causes an encephalopathic syndrome similar to that seen in man. Blood levels of bismuth should not exceed $20 \mu \mathrm{g}$ per $\mathrm{L}(20 \mathrm{ppb}) . "$

In their review, Slikkerveer and de Wolff (1989) summarized the effects of $\mathrm{Bi}$ in mammals and reported a peak of $\mathrm{Bi}$ in blood 45 minutes after oral dosing with colloidal $\mathrm{Bi}$ in humans. Others had reported peaks between 4.7-21 $\mu \mathrm{g} / \mathrm{g} 15-60$ minutes after dosing. With continued dosing, $3-$ 4 weeks were necessary to reach a steady-state of $\mathrm{Bi}$ in plasma. Persons who had not received $\mathrm{Bi}$ therapy had between 1 and $15 \mu \mathrm{g} / \mathrm{L}$ of $\mathrm{Bi}$ in their blood. Although the site of $\mathrm{Bi}$ absorption in the gastrointestinal tract is unknown, Slikkerveer and de Wolff believed that absorption after oral dosing is dependent on solubility and that cysteine, sorbitol, and lactic acid may promote absorption of $\mathrm{Bi}$. They suggested that colloidal Bi is absorbed in the small bowel and stomach.

Meaningful reference values for Bi levels in tissues are not available because of large variations in experimental and analytical techniques, and the chemical form of $\mathrm{Bi}$ in blood is unknown. The highest concentrations of $\mathrm{Bi}$ were always in the kidney. After 14 months of dosing with colloidal Bi subcitrate in rats, Bi concentrations ranked from high to low in kidney, lung, spleen, liver, brain, and muscle tissues. When bone concentrations were measured, they were usually 10-20 times lower than in the kidney.

Slikkerveer and de Wolff (1989) reported that $\mathrm{Bi}$ is found in both urine and feces. The $\mathrm{Bi}$ in feces 
comes from Bi excreted in bile, which concentrates plasma Bi by a factor of 10 , and from intestinal secretion. In humans showing symptoms of Bi toxicity after exposure, concentrations in bone were $1.5-6.7 \mu \mathrm{g} / \mathrm{g}$ wet weight compared with $<1$ $\mu \mathrm{g} / \mathrm{g}$ wet weight in nonexposed individuals. Bi encephalopathy is mainly supported by elevated blood Bi. A steady-state Bi concentration of $>100$ $\mu \mathrm{g} / \mathrm{L}$ (ppb) of blood in humans was arbitrarily suggested as an "alarm" level and $50 \mu \mathrm{g} / \mathrm{L}$ was considered a "safety" level, but no proof supports these choices. Concentrations of blood Bi from 10 to $4,600 \mu \mathrm{g}$ / $\mathrm{L}$ were found in $618 \mathrm{Bi}$ encephalopathy patients.

Abbracchio et al. (1985) administered tri-potassium-dicitrato bismuthate intraperitoneally and by gavage in laboratory rats. After intraperitoneal injection, $\mathrm{Bi}$ reached peak concentrations in blood within 30 minutes and declined rapidly. When a dose 10 times higher was given by gastric intubation, much lower blood concentrations were detected. They found no Bi in the brain after oral administration and concluded that there was apparently little risk of neurotoxicity after dosing with this derivative. They stated (p. 143), "This could also be the reason why no appreciable side effects have ever been described after use of this drug in humans."

Gregus and Klaassen (1986) reported that feces and urine were equally important for the excretion of injected Bi compounds in rats. Biliary excretion apparently determined the fecal excretion of $\mathrm{Bi}$, but the percentage of dosed $\mathrm{Bi}$ excreted in the bile was independent of the amount dosed.

Woods and Fowler (1987) reported that little information was available on the effects of $\mathrm{Bi}$ in mammals in general, but noted that toxic effects in the liver, kidneys, and blood have been found in humans and laboratory animals after exposure to $\mathrm{Bi}$ compounds. In their studies with rats ( $\mathrm{P}$. 276), they found that "...bismuth significantly impairs the activities of both hepatic ALA synthetase and heme synthetase at all dose levels."

Ross et al. (1988) injected 2,500 $\mu \mathrm{g} / \mathrm{g}$ of $\mathrm{Bi}$ subnitrate intraperitoneally in laboratory mice. Although Bi concentrations in blood and brain tissues of mice that showed signs of neurotoxicity were significantly higher than in dosed mice that showed no signs, they concluded that the concentration of $\mathrm{Bi}$ in blood did not predict neurologic signs. They suggested that $6 \mu \mathrm{g} / \mathrm{g}$ of $\mathrm{Bi}$ in the brain show neurologic symptoms and that a concentration of $\geq 0.5-2.0 \mu \mathrm{g} / \mathrm{g}$ of $\mathrm{Bi}$ in blood had to be maintained for several weeks to accumulate enough $\mathrm{Bi}$ in the brain to cause neurotoxicity.
They also concluded that $5-10 \mu \mathrm{g} / \mathrm{g}$ Bi in the brain was associated with motor dysfunction in humans and mice and that concentrations above 50 $\mu \mathrm{g} / \mathrm{L}(\mathrm{ppb})$ are necessary to produce frank encephalopathy in humans.

Slikkerveer and de Wolff (1989) reported, however, that following oral dosing of trimethyl $\mathrm{Bi}$ to dogs, the level of $\mathrm{Bi}$ was higher in the liver than in the kidney, probably because of the organic character of the molecule. They reported that early toxic effects of $\mathrm{Bi}$ may be related to effects on enzymes of the haem synthesis but that anemia has never been associated with ingestion of Bi.

\section{Methods}

The $\mathrm{Bi} / \mathrm{Sn}$ shot used in this study contained $0.0040 \%$ to $0.0186 \% \mathrm{~Pb}(\bar{x}=0.0094 \%, \mathrm{SD}=0.0054 \%)$. Because $\mathrm{Pb}$ made up $<0.1 \%$ of the test shot, Environment Canada (1992) guidelines did not require that tissues be analyzed for $\mathrm{Pb}$. We recognized, however, that researchers are interested in $\mathrm{Pb}$, so we included this metal, albeit at a somewhat high detection limit, in the analyses for residues.

Seventy-five female and 75 male wild-type game-farm mallards 6 to 8 months of age were purchased from Whistling Wings, Hanover, Illinois. The ducks, reared on a 60 -acre lake, were transported from Hanover to Champaign, Illinois, by truck in crates on 22 March 1994.

\section{Toxicity Study}

The ducks were weighed and one duck was randomly assigned to each pen. Forty ducks (20 females and 20 males) were randomly assigned to one of the three treatments-dosed with Bi shot, dosed with $\mathrm{Fe}$ shot, or sham dosed with 0 shot (controls). Five male and five female ducks were randomly selected from each dosing group for collection of feces to be analyzed for excreted $\mathrm{Bi}$, $\mathrm{Fe}$, and Sn. Sanderson et al. (1997b) describe the methods we used to randomize the doses, ducks, and pen assignments for the present study.

The pens were consecutively numbered, elevated, outdoor, $1-\mathrm{m}^{2}$ structures. They were covered with vinyl-coated, $25.4-\mathrm{mm}$ mesh, 14-gauge wire. A 9.1-m $\times 36.6-\mathrm{m}$ pavilion (roof but no sides) covered the pens (see Sanderson et al. 1992 for more details).

Facilities for holding the ducks were inspected and approved by several members of the Laboratory Animal Care Committee, University of Illinois, after the ducks were placed in the pens. The 
committee also inspected the facilities once during the study. Commercial duck pellets (Heinhold 17\% Duck Finisher Pellet ${ }^{\mathrm{TM}}$, Heinhold Feeds, Inc., Kouts, Indiana) were provided ad libitum during the 3-week acclimatization period. The duck pellets contained a minimum of $17.0 \%$ protein. On the date of dosing, the pellets were replaced with whole shelled corn ad libitum for the duration of the study. Protocols of the CWS and the USFWS specified these diets (Environment Canada 1992).

The three groups of ducks were each dosed as follows: sham dosed (controls); six, No. 4 (3.30 mm diameter), Fe shot; or six, No. 4, Bi shot. Ducks in each group are hereafter referred to as 0 dosed (controls), Fe-dosed, and Bi-dosed.

We began the study on 12 April 1994 (Day 0) when we weighed, collected blood samples, and dosed the ducks. A small plastic funnel fitted with a plastic tube ( $9.5 \mathrm{~mm}$ outside diameter, 22.9 $\mathrm{cm}$ long) was inserted through the pharynx into the proventriculus. To reduce friction, the tube was kept in a pail of water between dosings. Each dose of shot was poured into the funnel and flushed into the proventriculus with approximately $5 \mathrm{~mL}$ of water. Controls were treated the same except that no shot were included. Before dosing, the shot were counted, weighed, and placed in individual vials in the laboratory. The type, number, and weight of each dose of shot were recorded on the top of each vial and on a computer printout for each duck. At dosing, the shot dose was matched with the corresponding duck.

Blood was collected from the wing vein in heparinized microhematocrit capillary tubes for hematocrit determination and in $2.5-\mathrm{mL}$ syringes for separation into cells and plasma. The plasma samples were analyzed for major elements ( $>1 \%$ by wt in shot) and for major nutritionally essential elements ( $\mathrm{Ca}, \mathrm{P}, \mathrm{Mg}, \mathrm{Zn}$, and $\mathrm{Cu}$ ). Twenty-gauge, 25.4-mm needles were used (Baxter Healthcare Corporation, Scientific Products Division, McGaw Park, Illinois). The whole blood was injected into 10 -mL lithium heparinized VacutainerTM tubes and centrifuged to separate cells and plasma. Body weights were recorded and blood samples collected on Days 0, 15, and 30.

As each group of 24 hematocrit samples was collected, the samples were centrifuged at the site in a mobile laboratory (house trailer). The tubes were spun for 5 minutes at 11,500 RPM at 13,000$\mathrm{g}$ force, after which the values were read and recorded.

The whole blood samples also were centrifuged at the site, in groups of 12 samples (capacity of the centrifuge) at a time. The tubes were spun for 5 minutes at 3,000 RPM. The plasma was removed with micropipettes and placed in 5-mL nonheparinized Vacutainer tubes. The cells were retained in the $10-\mathrm{mL}$ lithium heparinized tubes. As the plasma and cells were separated, the tubes were placed in racks and put on ice in a styrofoam cooler. All samples were stored in a freezer $\left(-10^{\circ} \mathrm{C}\right)$ until analyzed.

The Bi shot were provided by William $\mathrm{S}$. Montgomery, Jr., Bismuth Cartridge Co., Dallas, Texas. Seven shot were chemically analyzed in the laboratory of the Illinois State Water Survey, Champaign, Illinois, before the ducks were dosed. Mean $( \pm S D)$ percentages of elements in these shot were as follows: $\mathrm{Bi}=98.35 \%, \pm 0.86 \%$; and $\mathrm{Sn}=$ $1.90 \%, \pm 0.10 \%$. Other elements averaged $<0.1 \%$ each; $\overline{\mathrm{Pb}}$ ranged from $0.0040 \%$ to $0.0186 \%$ $(\bar{x}=0.0094 \%, \pm 0.0054 \%)$. Fe shot were removed from commercial 12-gauge shotgun shells and were not analyzed.

The 120 ducks were weighed and blood was collected from the wing veins, as scheduled, on Day 30 (12 May 1994). Following these procedures, the ducks were killed by decapitation and necropsied on the same day (with the exception noted below). The gizzard, liver, kidneys, and gonads were excised from each duck.

Two changes were made in the methods as originally approved by the CWS. First, because voided shot were not found in the feces, 20 dosed ducks were radiographed to obtain a positive record of shot retention in the gizzards. The 20 ducks for which daily fecal samples were being collected were chosen so that fecal material could be re-examined if the radiographs indicated dosed shot were missing from the gizzards. A dorsalventral and a right or left lateral view radiograph were made for each duck on Day 23 (5 May 1994) by the College of Veterinary Medicine, University of Illinois.

The other change in the methods involved killing the ducks and performing the necropsies over 2 days (instead of 1 ) to ensure that tissue samples were obtained from freshly killed birds. The pathologist necropsied 30 ducks on 12 May and the other 30 ducks on 13 May 1994.

After the pathologist had examined, weighed, and fixed representative samples of kidneys, liver, and gonads in $10 \%$ formalin for histopathology, the remaining residual tissue from these organs was placed in separate, numbered, plastic bags and stored in a freezer as backup samples. Organs from the remaining 60 ducks, which were not necropsied, were removed and weighed, placed 
in individual, numbered, plastic bags, and stored in the freezer as additional backup samples.

We took representative samples, after fixing in $10 \%$ formalin, from each of the 60 necropsied ducks and examined the samples histopathologically. Sections of gonad (testis or ovary), liver, kidney, and gizzard were embedded, trimmed, and sectioned at 4 microns. Tissues on glass slides were stained with hematoxylin and eosin by standard methods. All ducks were examined by a veterinary pathologist, who did not know the dose history of the ducks. Later, we associated group assignment and weight data with histologic findings to aid in interpretation.

\section{Chemical Analyses}

\section{Storage of Samples}

Samples were inventoried when received, stored at $-10^{\circ} \mathrm{C}$, and monitored daily. Samples were allowed to thaw to room temperature, then prepared for metal analysis by labelling by tissue type and a number for identification. The sex of the duck and the shot dose it received were not disclosed to the individuals who analyzed the samples.

\section{Digestions of Samples}

Blood cells, blood plasma, livers, kidneys, gonads, and feces were acid digested before analysis for metals with inductively coupled, argon-plasma emission spectroscopy (ICP) and graphite-furnace, atomic-absorption spectroscopy (GFAA). Because wet weight concentrations of the blood and organs were desired, these samples were not dried before digestion. Feces were dried at $104^{\circ} \mathrm{C}$ to determine percent moisture. The concentrations of metals measured in fecal samples are on a dry-weight basis. We analyzed for $\mathrm{Bi}, \mathrm{Sn}, \mathrm{Fe}, \mathrm{Pb}$, $\mathrm{Ca}, \mathrm{Mg}, \mathrm{P}, \mathrm{Zn}$, and $\mathrm{Cu}$. ICP was used to measure these metals; beryllium (Be) was used as an internal standard. GFAA was used to measure $\mathrm{Pb}$ and $\mathrm{Bi}$ when they were at low concentrations.

\section{Digestions for ICP Analysis}

We used samples of 0.5 to $1.0 \mathrm{~g}$. A mixed portion of the sample was weighed to $1.0 \mathrm{mg}$ with an electronic, top-loading balance and placed into a tared 50 -mL conically tipped polypropylene, centrifuge tube. The tubes were precleaned for $24-\mathrm{hr}$ with a $10 \%$ nitric acid $\left(\mathrm{HNO}_{3}\right)$ soak then rinsed in deionized water. Samples of feces were weighed to $0.1 \mathrm{mg}$. Approximately 30 to $50 \mathrm{~mL}$ of an acid and internal standard solution were added to the sample after taring. The final acid concentrations were $2 \% \mathrm{HNO}_{3}$ and $10 \%$ hydrochloric acid $(\mathrm{HCl})$.
The Be concentration was targeted at $2.00 \mathrm{mg} / \mathrm{L}$. The samples were then homogenized into a slurry using a saw-toothed generator made of titanium and TFE-fluorocarbon (Pro Scientific, Monroe, Connecticut). The internal standard solution was used to rinse excess materials from the generator and the amount was accounted for in the total weight.

Samples were prepared with the SpectrPrep System ${ }^{\mathrm{TM}}$, an automated microwave-digestionsystem (CEMCorporation, Matthews, North Carolina). A $15-\mathrm{mL}$ sample loop was used. After heating, cooling, and filtering, about $12.5 \mathrm{~mL}$ of the sample were collected and deposited by autosampler into $15 \mathrm{~mL}$ polypropylene test tubes. This digestate without further treatment was then used for ICP analysis. The automated microwave digestion system was a relatively new technique to prepare samples. A few problems arose in adjusting to the system; most were associated with clogging of the small-diameter tubing. A thorough homogenation followed by a few hours in a warm, ultrasonic bath usually improved the operation.

\section{Digestions for GFAA Analysis}

We used samples of 0.5 to $1.0 \mathrm{~g}$. A mixed portion of the sample was weighed to $1.0 \mathrm{mg}$ with an electronic, top-loading balance and placed into a tared TFE-fluorocarbon beaker. Approximately $20 \mathrm{~mL}$ of deionized water $\left(\mathrm{DI} \mathrm{H}_{2} \mathrm{O}\right), 0.250 \mathrm{~mL}$ concentrated $\mathrm{HNO}_{3}$, and $1 \mathrm{~mL}$ of hydrogen peroxide $\left(\mathrm{H}_{2} \mathrm{O}_{2}\right)$ were added. The mixture was heated at approximately $95^{\circ} \mathrm{C}$ until the solution started to clear (about $0.5 \mathrm{hr}$ ). Approximately $20 \mathrm{~mL}$ of DI $\mathrm{H}_{2} \mathrm{O}$ and $2 \mathrm{~mL} \mathrm{H}_{2} \mathrm{O}_{2}$ were added. Upon further heating the mixture cleared and "foamed up." DI $\mathrm{H}_{2} \mathrm{O}$ was used to rinse contents from the sides of the beaker. The beakers were then covered with TFE-fluorocarbon watch glasses and allowed to reflux for approximately $l \mathrm{hr}$. The resulting solutions were usually clear to yellow. The samples were increased to $50 \mathrm{~mL}$ in a volumetric flask, filtered through $0.45-\mu \mathrm{m}$ nitrocellulose filters, and stored in acid-washed, linear, polyethylene bottles. The ultimate acid concentration was $0.5 \% \mathrm{HNO}_{3}$. High-purity acids and hydrogen peroxide (Baker Ultrex ${ }^{\mathrm{TM}}$ and Fisher OptimaTM) were used for all digestions.

\section{Analytical Methods \\ ICP}

We used a ThermoJarrell Ash (TJA) AtomComp ${ }^{\mathrm{TM}}$, Model 61, vacuum spectrometer. The instrument has a polychromator configured with 44 fixed 
channels, including analytical lines for high and low concentrations of $\mathrm{Ca}$ and $\mathrm{Mg}$. Although we reported results for only a few elements, we measured 30 analytes to monitor for spectral interferences, which we did not detect, with blank subtraction and background correction.

We used USEPA Method 200.7, Revision 4.4, Determination of Metals and Trace Elements in Water and Wastes by Inductively Coupled PlasmaAtomic Emission Spectroscopy for our work. We modified the method and used a different digestion process, and we measured $\mathrm{Bi}$, not a listed analyte. We chose Be as an internal standard because it was not present in the samples, it does not cause spectral or background interferences, and it is precisely detectable.

\section{GFAA}

We used a Thermo Jarrell Ash, Model957, Atomic Absorption Spectrophotometer coupled with a Model 188, Furnace Atomizer and FASTACтм autosampler. Samples were introduced as a spray and deposited directly into a carbon cuvette at $100^{\circ} \mathrm{C}$ so that samples dried on contact. We used method 3113 of Greenberg et al. (1992). We analyzed samples in triplicate and reported the mean.

\section{Quality Control}

We calibrated instruments daily and we verified the standard curve using National Institute of Standards and Technology (NIST) traceable, quality control samples (QCS). Samples (usually 10) were bracketed by calibration blanks, laboratory fortified blanks, and instrument-performance, check solutions during analysis as well as periodic checks on the internal-standard solution. The ICP instrument was programmed to compensate for drift by recalculating the slopes of the calibration curves if any analyte was more than $\pm 5 \%$ of the true value while measuring the ICP check standard. If an analyte measured greater than $\pm 10 \%$ of the true value for this sample, the instrument was recalibrated and the affected samples reanalyzed. The ICP check standard was formulated for a concentration at the midpoint of the calibration curve. It was traceable to NIST Standard Reference Materials (SRMs). The GFAA QCS initially were required to be within $10 \%$ of the true value. Subsequent measurement of the bracketed internals was required to be $\pm 15 \%$. If these limits were exceeded, the instrument was recalibrated and the affected samples reanalyzed.

Ten percent of the samples were digested and analyzed in duplicate, half of them spiked. Additional liver samples were treated as dupli- cates as part of the process of evaluating the automated, microwave-digestion equipment. Digestion blanks and spiked digestion blanks were prepared at a frequency of $10 \%$. They were processed through the complete digestion and analytical system in the same manner as the samples.

\section{Calculations}

We saved the ICP data during analysis in database files with ThermoSpec (TJA) software utilizing Enable OA. Data were then imported into Enable spreadsheets for tabulations and calculations. The Enable spreadsheets were saved in a Lotus 1-2-3 format on diskette. The GFAA results were recorded on an instrument printer as concentrations in $\mu \mathrm{g} / \mathrm{L}$ based upon peak-area measurements. These data were manually entered into spreadsheets for tabulations and calculations.

The Method Detection Limit (MDL) (Glaser et al. 1981) was used to establish the detection limits for concentrations of elements in tissues and other materials. Glaser et al. (1981:1426) describe the MDL as "a new performance criterion for chemical analysis . . . defined as that concentration of the analyte that can be detected at a specific confidence level." Also, "The detection limit should be related to the standard deviation of the measured value at or near zero concentration of the analyte ...." They further report (1427), "MDL is considered operationally meaningful only when the method is truly in the detection mode, i.e., analyte must be present. The method detection limit is defined as the minimum concentration of a substance that can be identified." To be considered a meaningful difference, the MDL procedure is required to provide a value that averages $\geq$ two times the MDL (Glaser et al. 1981). For statistical analysis, values < MDL were entered as one-half the MDL value.

Most values for elements in the tissues were determined by ICP. Results of ICP analyses for Bi, $\mathrm{Pb}$, and $\mathrm{Sn}$ were usually lower than the MDLs. Thus, selected samples of kidneys, livers, and gonads were analyzed for $\mathrm{Bi}$ and $\mathrm{Pb}$ by GFAA. The remaining amounts of plasma and blood cells after analysis by ICP were inadequate for further analysis by GFAA. Graphite-furnace atomic absorption is not a satisfactory method to analyze for $\mathrm{Sn}$.

\section{Statistical Analyses}

In this report, when two values are reported as "different" or that they "differ," it means that they differ in a statistical sense at an alpha of $(P \leq 0.05)$. 
Differences in concentrations of various elements in livers, kidneys, and gonads; weights of organs (post-mortem); numbers of shot recovered; and dissolution rates of shot were tested by one- or two-way ANOVA using sex and dose (shot type) as grouping factors. Homogeneity of variances among groups was assessed with Levene's test. Brown-Forsythe or Welch statistics were used in instances where variances could not be assumed equal. In instances where the overall test of differences among groups was significant, pairwise comparisons were performed and significance evaluated based on the Bonferroni correction. In instances where comparisons were made with controls, Dunnett's procedure was used.

Variation in body weights, hematocrit counts, and concentrations of elements in plasma and red blood cells (all measured at Days 0, 15, and 30) were evaluated using repeated-measures ANOVA. As above, sex or dose or both, were used as between-subject factors. Within-subject tests for variation over time were also performed as were tests for interactions between dose and time. When assumptions of compound symmetry were violated, Huynh-Feldt-adjusted significance probabilities were used.

\section{Results}

\section{Survival}

All 120 ducks (controls, Bi-dosed, and Fe-dosed) survived to the end of the 30-day test period.

\section{Retention and Dissolution of Shot}

No voided shot were found in the feces from the 20 dosed ducks ( 5 female and 5 male Bi-dosed and 5 female and 5 male Fe-dosed ducks) for which feces were saved for chemical analysis. Radiographs on Day 23 readily identified all six shot in the gizzard of each of these ducks.

Six pellets, which were sometimes dissolved to small disks, were recovered from 38 of the $40 \mathrm{Bi}$ dosed ducks. One male contained only five Bi disks in his gizzard. Because most of the shot were highly dissolved, it is probable that the sixth pellet had dissolved. A second male contained four tiny Bi particles in his gizzard. The combined particles of Bi weighed only $42.1 \mathrm{mg}$, and the fifth and sixth pellets probably had dissolved.

Six pellets were recovered from 35 of the 40 Fe-dosed ducks. One female had five tiny pellets in her gizzard that weighed $77.7 \mathrm{mg}$. This duck had the second highest $(2,339 \mu \mathrm{g} / \mathrm{g})$ concentra- tion of Fe in the liver. The mean concentration of Fe in livers of Fe-dosed ducks was $1086 \mu \mathrm{g} / \mathrm{g}$. Thus, the sixth pellet undoubtedly had dissolved. One female contained no shot in her gizzard, but she had $1,782 \mu \mathrm{g} / \mathrm{g}$ Fe in the liver. This duck probably also had dissolved the shot. The remaining three ducks, one male and two females, each contained five pellets in their gizzards. All of these pellets were small, collectively weighing from 147.4 to $282.9 \mathrm{mg}$ for each duck. One of these females had the highest concentration $(2,412 \mu \mathrm{g}$ / g) of Fe in her liver of any duck. The other two ducks contained $645 \mu \mathrm{g} / \mathrm{g}$ and 1,043 $\mu \mathrm{g} / \mathrm{g}$ Fe respectively, in their livers. The sixth pellet in each of these three ducks may have been voided, but they probably were dissolved. None of the dosed ducks with missing shot in their gizzards was among the ducks that were radiographed and for which feces were saved for analysis.

The retained $\mathrm{Bi}$ and $\mathrm{Fe}$ shot differed in appearance. The Fe shot were usually round, although many were pitted or had empty spaces on their surfaces, whereas the Bi shot were generally disk-shaped or flattened. In several instances, five Bi disks plus two, three, or four tiny pieces (not flakes) of Bi were recovered from the gizzard. Obviously, when a Bi disk became thin enough, it disintegrated into several pieces. A small number of flakes of $\mathrm{Bi}$ were found in a few gizzards. This finding for $\mathrm{Bi} / \mathrm{Sn}$ alloy shot is in contrast to the abundance of tiny flakes of $\mathrm{Bi}$ found in the dosing study that used 100\% Bi shot (Sanderson et al. 1992).

The dissolution rates were variable in both Fe-dosed and Bi-dosed ducks. Based on the shot recovered from the gizzards on Day 30, females dosed with Bi shot dissolved a mean of $69.5 \%$ and males $72.5 \%$ (Table 1 ) of the metal's original weight in 30 days (dissolution in individual ducks ranged from $38.2 \%$ to $96.4 \%$ ). No difference between the sexes was detected for Bi-dosed ducks. Fe-dosed females dissolved an average of $69.2 \%$ and Fedosed males $55.6 \%$ of the metal's original weight in 30 days (range for individual doses was from $38.0 \%$ to $89.6 \%$ ). The different dissolution rates between sexes for Fe-dosed ducks was expected (Table 1). Females approaching the breeding season in spring eat more food than males and thus produce more acid in their gizzards. As a result, Fe shot, which dissolve readily in the acid $(\mathrm{HCl})$ environment of the gizzard, dissolve more rapidly in females than in males during this season.

Males dissolved more of the weight $(72.5 \%)$ of the Bi shot than of the Fe shot (55.6\%) in 30 days. 
Females dissolved no more $(69.5 \%)$ of the weight of the Bi shot than of the Fe shot $(69.2 \%)$ in 30 days. An interaction, which was caused by the lower rate of dissolution of Fe shot by males as compared with the dissolution rate of Fe shot by females and no difference in the dissolution rates of Fe shot and Bi shot by females, existed between sex and dose (Table 1).

\section{Body Weight}

All groups of dosed ducks, except Bi-dosed males, lost from 1.8 to $5.0 \%$ of their body weight during the 30 -day study. All groups lost from 4.5 to $9.6 \%$ of their body weight from Day 0 to Day 15, probably because of the switch from duck pellets to a whole corn diet. By Day 30, most of the birds had regained weight lost after the change in diet. $\mathrm{Bi}$ dosed males gained only $1.6 \%$ in body weight from Day 0 to Day 30 (Table 2).

Males weighed more than females, and an interaction in weight between sex and time existed, with females losing a larger percentage of their weight from Day 0 to Day 30 than males. Although ducks lost weight over time, the average weight losses for females from Day 0 to Day 30 were only $-3.8 \%$ for 0 -dosed, $-3.8 \%$ for Fe-dosed, and $-5.0 \%$ for $\mathrm{Bi}$-dosed females. The average weight changes for males from Day 0 to Day 30 were $-1.8 \%$ for 0 -dosed, $-3.2 \%$ for Fe-dosed, and $+1.6 \%$ for Bi-dosed ducks. No difference existed in body weights among doses (Table 2).

\section{Organ Weights}

Gizzard

Mean gizzard weights ranged from $29.3 \mathrm{~g}$ for $\mathrm{Fe}-$ dosed females to $32.2 \mathrm{~g}$ for Bi-dosed males (Table 3). No difference was detected in the weight of gizzards between sexes or among doses.

As a percentage of total body weight, mean gizzard weights ranged from $2.5 \%$ for each of $\mathrm{Fe}-$ dosed and Bi-dosed males to $3.0 \%$ for 0 -dosed females (Table 3). Gizzards of females contributed a higher percentage of the total body weight than males. No difference was recorded among doses in the percentage that gizzards contributed to total body weight.

\section{Liver}

Mean weights of livers ranged from $19.3 \mathrm{~g}$ for $\mathrm{Bi}$ dosed females to $21.7 \mathrm{~g}$ for Fe-dosed females. No differences existed between sexes or among doses (Table 4).

When considered as a percentage of total body weight, mean values for livers ranged from $1.6 \%$ for $\mathrm{Bi}$-dosed and 0 -dosed males to $2.0 \%$ for
Fe-dosed and 0-dosed females. Livers of females comprised a higher percentage of the total body weight than the livers of males. No difference was detected among doses in the mean percentage that livers contributed to the total body weight.

\section{Kidneys}

Weights of kidneys, the organ most involved in excretion of $\mathrm{Bi}$, differed least between sexes and varied least among doses of the organs weighed. Mean weights of kidneys ranged from $6.4 \mathrm{~g}$ for $\mathrm{Bi}-$ dosed females, Bi-dosed males, and Fe-dosed females to $6.6 \mathrm{~g}$ for 0 -dosed males (Table 5). No differences were found between sexes or among doses in the weights of kidneys.

As with weights of livers, when kidney weights were expressed as a percentage of total body weight, sex differences were detected. Mean percentages ranged from $0.5 \%$ for each group of males to $0.6 \%$ for each group of females. Kidneys of females comprised a larger percentage of the total body weight than males, but no differences existed among doses.

\section{Gonads}

No differences among doses in the mean weights of gonads were found (Table 6). As was expected, mean weights of gonads differed between the sexes: $6.4 \mathrm{~g}$ for 0 -dosed females, versus $26.4 \mathrm{~g}$ for 0 -dosed males; $10.1 \mathrm{~g}$ for Fe-dosed females, versus $28.0 \mathrm{~g}$ for Fe-dosed males; and $4.3 \mathrm{~g}$ for $\mathrm{Bi}$ dosed females versus $22.5 \mathrm{~g}$ for Bi-dosed males. These sex differences also were evident in gonad weights when expressed as a percentage of total body weight; the means ranged from $0.4 \%$ for $\mathrm{Bi}$ dosed females to $2.4 \%$ for Fe-dosed males (Table 6). No differences appeared among doses, but male gonads contributed a larger percentage of the total body weight than did the female gonads.

\section{Hematocrit (Hct)}

Mean hematocrits were not different among doses for the three sample times: Days 0, 15, and 30 (Table 7). The mean percentage changes in Hct values from Day 0 to Day 30 did not differ between the sexes. With sexes combined the mean percentage change in Hct from Day 0 to Day 30 increased $(P<0.00001)$ by $6.6 \%$ for controls, $11.8 \%$ for Bi-dosed ducks, and $12.8 \%$ for Fe-dosed ducks.

\section{Heavy Metals and Essential Elements in Organs and Blood}

For consistency in presentation of the data, usually the mean concentrations of elements in each organ or tissue for each sex and for sexes com- 
Table 1. Percent of the dosed shot accounted for and mean percent of weight of dosed shot dissolved in 30 days in the gizzard — six, No. 4, Fe shot or six, No. 4, Bi shot— in female and male game-farm mallards ( $\mathrm{n}=20$ females and 20 males in each dosed group).

\begin{tabular}{llll}
\hline Sex & Dose & $\begin{array}{l}\text { \% of Dosed Shot } \\
\text { Accounted for }\end{array}$ & $\begin{array}{l}\text { Mean \% Wt of } \\
\text { Shot Dissolved }\end{array}$ \\
\hline $\mathrm{F}$ & $\mathrm{Fe}$ & 93.3 & 69.2 \\
& & $5.04^{\mathrm{b}}$ & 2.84 \\
$\mathrm{M}$ & $\mathrm{Fe}$ & 99.2 & 55.6 \\
& & 0.84 & 2.22 \\
$\mathrm{~F}$ & $\mathrm{Bi}$ & 100.0 & 69.5 \\
& & 0.00 & 4.01 \\
$\mathrm{M}$ & $\mathrm{Bi}$ & 97.5 & 72.5 \\
& & 1.82 & 3.59 \\
\hline
\end{tabular}

a Based on the shot recovered from the gizzards on Day 30 ,

when the ducks were killed.

b SE.

Interaction between sex and dose: $\quad \mathrm{F}_{1,60}=4.53 ; P=0.0374$.

Difference between sexes for percent of $\mathrm{Fe}$ shot dissolved in

30 days:

$$
\mathrm{F}_{1,37}=14.89 ; P=0.0014 \text {. }
$$

Difference between doses for males: $\quad \mathrm{F}_{1,31}=17.42 ; P=0.0002$.

Table 2. Mean body weight on Days $0^{\mathrm{a}}, 15$, and $30^{\mathrm{b}}$ of female and male game-farm mallards each dosed with 0 shot; six, No. 4, Fe shot; or six, No. 4, Bi shot, and mean percentage change in body weight from Day 0 to Day $30(n=20$ females and 20 males in each group).

\begin{tabular}{llllll}
\hline & & & \multicolumn{2}{c}{ Mean Body Weight $(\mathrm{Kg})$} & \\
Sex & Dose & Day 0 & Day 15 & Day 30 & $\begin{array}{c}\text { Mean \% change in body } \\
\text { wt-Day 0 to Day 30c }\end{array}$ \\
\hline F & 0 & 1.11 & 1.06 & 1.06 & -3.8 \\
& & $0.024^{\mathrm{d}}$ & 0.027 & 0.030 & 1.12 \\
$\mathrm{M}$ & 0 & 2.24 & 1.19 & 1.22 & -1.8 \\
& & 0.020 & 0.025 & 0.022 & 1.38 \\
$\mathrm{~F}$ & $\mathrm{Fe}$ & 1.10 & 1.04 & 1.05 & -3.8 \\
& & 0.020 & 0.018 & 0.021 & 0.97 \\
$\mathrm{M}$ & $\mathrm{Fe}$ & 1.24 & 1.18 & 1.20 & -3.2 \\
& & 0.023 & 0.027 & 0.025 & 1.12 \\
$\mathrm{~F}$ & $\mathrm{Bi}$ & 1.08 & 1.02 & 1.03 & -5.0 \\
& & 0.026 & 0.025 & 0.026 & 1.11 \\
$\mathrm{M}$ & $\mathrm{Bi}$ & 1.23 & 1.21 & 1.24 & +1.6 \\
& & 0.019 & 0.025 & 0.039 & 2.31 \\
\hline
\end{tabular}

a Ducks were dosed on Day 0.

${ }^{b}$ Ducks were killed on Day 30.

c Because of rounding error, these means are sometimes slightly different than if calculated by differences in the Day 0 and Day 30 columns.

d SE.

Mean body weight:

Difference between sexes:

$F_{1,114}=66.42 ; P<0.00001$.

Interaction between sex and time:

$F_{2.228}=3.21 ; P=0.0471$.

Difference among doses:

$F_{2,114}=0.11 ; P=0.8995$.

Change over time:

$F_{2,228}=33.17 ; P<0.00001$. 
Table 3. Mean weight of gizzard and mean percentage it contributed to total body weight in game-farm mallards 30 days after dosing with 0 shot; six, No. 4, Fe shot; or six, No. 4, Bi shot ( $\mathrm{n}=20$ females and 20 males in each group).

\begin{tabular}{llll}
\hline Sex & Dose & $\begin{array}{l}\text { Mean } \\
\text { Weight }(\mathrm{g})\end{array}$ & $\begin{array}{l}\text { Mean \% of } \\
\text { body wt }\end{array}$ \\
\hline $\mathrm{F}$ & 0 & 31.8 & 3.0 \\
& & $1.04^{\mathrm{a}}$ & 0.07 \\
$\mathrm{M}$ & 0 & 31.6 & 2.6 \\
& & 0.75 & 0.08 \\
$\mathrm{~F}$ & $\mathrm{Fe}$ & 29.3 & 2.8 \\
& & 1.07 & 0.08 \\
$\mathrm{M}$ & $\mathrm{Fe}$ & 30.7 & 2.5 \\
& & 0.98 & 0.08 \\
$\mathrm{~F}$ & $\mathrm{Bi}$ & 30.2 & 2.8 \\
& & 1.00 & 0.13 \\
$\mathrm{M}$ & $\mathrm{Bi}$ & 32.2 & 2.5 \\
& & 1.08 & 0.13 \\
\hline
\end{tabular}

a SE.

Difference among doses in weight of gizzard:

$F_{2,14}=1.50 ; P=0.2265$.

Difference between sexes in percentage gizzard

contributed to total body weight:

$F_{1,114}=34.43 ; P<0.00001$.

Difference among doses in percentage gizzard contributed to total body weight:

$F_{2,101}=1.99 ; P=0.1422$.

Table 4. Mean weight of liver and mean percentage it contributed to total body weight in game-farm mallards 30 days after dosing with 0 shot; six, No. 4, Fe shot; or six, No. 4, Bi shot $(n=20$ females and 20 males in each group).

\begin{tabular}{llll}
\hline & & $\begin{array}{l}\text { Mean } \\
\text { Weight(g) }\end{array}$ & $\begin{array}{l}\text { Mean \% of } \\
\text { body wt }\end{array}$ \\
\hline F & Dose & 21.1 & 2.0 \\
& 0 & $1.49^{\mathrm{a}}$ & 0.10 \\
$\mathrm{M}$ & & 20.0 & 1.6 \\
& 0 & 0.94 & 0.06 \\
$\mathrm{~F}$ & $\mathrm{Fe}$ & 21.7 & 2.0 \\
& & 1.54 & 0.12 \\
$\mathrm{M}$ & $\mathrm{Fe}$ & 20.5 & 1.7 \\
& & 0.94 & 0.08 \\
$\mathrm{~F}$ & $\mathrm{Bi}$ & 19.3 & 1.9 \\
& & 0.92 & 0.08 \\
$\mathrm{M}$ & $\mathrm{Bi}$ & 19.5 & 1.6 \\
& & 0.97 & 0.04 \\
\hline
\end{tabular}

a SE.

Difference among doses in weight of liver:

$$
F_{2,14}=1.10 ; P=0.3370 .
$$

Difference between sexes in percentage liver contributed to total body weight: $\quad F_{1,84}=22.21 ; P<0.00001$.

Difference among doses in percentage liver contributed to total body weight: $\quad F_{2,114}=1.80 ; P=0.1706$. 
continued from page 192

bined are listed in the tables. When no statistically significant differences existed between sexes, usually only $P$ values for the combined sexes are provided.

\section{Kidneys}

The MDL for analysis by ICP for Bi in kidneys was $17.8 \mu \mathrm{g} / \mathrm{g}$ (wet wt). The mean concentrations were $<$ MDL in kidneys of all but 2 of 120 ducks.

Because the MDL for Bi by ICP in the kidneys was unacceptably high, kidneys of 100 dosed and $11 \mathrm{Bi}$-dosed ducks were selected for analysis by GFAA. No sex differences were detected in the mean concentration of $\mathrm{Bi}$ in the kidneys of Bi-dosed ducks (Table 8). The mean concentration $(6.86 \mu \mathrm{g} / \mathrm{g})$ of $\mathrm{Bi}$ in the kidneys of Bi-dosed ducks, with sexes combined, was higher than the mean concentration of $\mathrm{Bi}$ in 0 -dosed ducks $(0.334 \mu \mathrm{g} / \mathrm{g})$. The mean concentration of $\mathrm{Bi}$ in the kidneys of Bi-dosed ducks was much higher than the mean concentration $(2.23 \mu \mathrm{g} / \mathrm{g})$ of $\mathrm{Bi}$ in the livers of Bi-dosed ducks (Table 10).

The MDL for $\mathrm{Pb}$ in the kidneys was $6.54 \mu \mathrm{g} /$ $\mathrm{g}$ (wet wt) by ICP. All mean values for $\mathrm{Pb}$ in the kidneys were < MDL by this method. By GFAA, no sex differences existed in the concentration of $\mathrm{Pb}$ in the kidneys of 0 -dosed or Bi-dosed ducks. No difference was found in the concentration of $\mathrm{Pb}$ in the kidneys of 10 (sexes combined) 0-dosed ducks $(0.440 \mu \mathrm{g} / \mathrm{g})$ compared with $11 \mathrm{Bi}$-dosed ducks $(0.313 \mu \mathrm{g} / \mathrm{g})$ (Table 8$)$.

The MDL for $\mathrm{Sn}$ in the kidneys was $9.47 \mu \mathrm{g} /$ $\mathrm{g}$ (wet wt). Only six ducks had concentrations of $\mathrm{Sn}>\mathrm{MDL}$. The mean concentration of $\mathrm{Sn}$ in the kidneys of these six ducks was $14.3 \mu \mathrm{g} / \mathrm{g}$ and ranged from 10.5 to $19.7 \mu \mathrm{g} / \mathrm{g}$. Three of these ducks were Bi-dosed $(\bar{x}=6.7 \mu \mathrm{g} / \mathrm{g})$, two were 0 dosed $(\bar{x}=1.0 \mu \mathrm{g} / \mathrm{g})$, and one was Fe-dosed (13.7 $\mu \mathrm{g} / \mathrm{g})$.

No difference existed between sexes in the mean concentrations of $\mathrm{Cu}$ in the kidneys (Table 9). With sexes combined, no differences were detected among doses in the mean concentration of $\mathrm{Cu}$ in the kidneys: $6.31 \mu \mathrm{g} / \mathrm{g}$ in 0-dosed, 7.31 $\mu \mathrm{g} / \mathrm{g}$ in Fe-dosed, and $6.14 \mu \mathrm{g} / \mathrm{g}$ in Bi-dosed ducks.

No sex differences existed in the mean concentrations of $\mathrm{P}$ in the kidneys (Table 9) and no differences existed among doses in the mean concentrations of $\mathrm{P}$ in the kidneys. However, an interaction was found between sex and dose.

No difference existed between sexes in the mean concentration of $\mathrm{Fe}$ in the kidneys (Table
9), but mean concentrations of Fe in the kidneys differed among doses. Fe-dosed ducks, sexes combined, had higher mean concentrations (145 $\mu \mathrm{g} / \mathrm{g}$ ) of Fe in their kidneys than 0-dosed ducks (123 $\mu \mathrm{g} / \mathrm{g})$ or Bi-dosed ducks (123 $\mu \mathrm{g} / \mathrm{g})$. No difference was detected in the mean concentrations of Fe in the kidneys of 0 -dosed and Bi-dosed females (Table 9).

Females, with doses combined, had higher mean concentrations of $\mathrm{Ca}$ in the kidneys than males, but no difference was found in the mean concentrations of $\mathrm{Ca}$ in the kidneys among doses. Mean concentrations of $\mathrm{Mg}$ in the kidneys did not differ between sexes, and with sexes combined, no difference existed among doses (Table 9).

Mean concentrations of $\mathrm{Zn}$ in the kidneys of 0 -dosed, Fe-dosed, and Bi-dosed ducks did not differ between sexes within each dose, but with doses combined, males had higher mean concentrations of $\mathrm{Zn}$ in the kidneys than females (Table 9). With sexes combined, mean concentrations of $\mathrm{Zn}$ in the kidneys varied among doses. Bi-dosed ducks had higher mean concentrations of $\mathrm{Zn}$ in their kidneys $(28.2 \mu \mathrm{g} / \mathrm{g})$ than Fe-dosed ducks (25.2 $\mu \mathrm{g} / \mathrm{g})$, but not higher mean concentrations than 0-dosed ducks (26.6 $\mu \mathrm{g} / \mathrm{g})$ (Table 9). No difference was detected in mean concentrations of $\mathrm{Zn}$ in the kidneys of 0-dosed and Fe-dosed ducks.

\section{Liver}

The MDL (by ICP) for Bi in livers was $18.45 \mu \mathrm{g} / \mathrm{g}$ (wet wt). No concentration of Bi exceeded the MDL in the liver of any duck. Analysis by GFAA produced values of $\mathrm{Bi}$ in the livers of $11 \mathrm{Bi}$-dosed ducks that averaged $2.23 \mu \mathrm{g} / \mathrm{g}(0.63$ to $5.63 \mu \mathrm{g} / \mathrm{g})$. Mean amounts of $\mathrm{Bi}$ in the liver (Table 10) were not different between sexes. With sexes combined, Bi-dosed ducks contained a higher $(2.23$ $\mu \mathrm{g} / \mathrm{g})$ mean amount of $\mathrm{Bi}$ in the liver than did 0dosed ducks $(0.193 \mu \mathrm{g} / \mathrm{g})$.

The MDL (by ICP) for Pb in the liver was 7.51 $\mu \mathrm{g} / \mathrm{g}$. The concentrations were all below the MDL. The concentration of $\mathrm{Pb}$ in the livers, as determined by GFAA, were from <MDL $(0.10$ $\mu \mathrm{g} / \mathrm{g}$ ) to $0.46 \mu \mathrm{g} / \mathrm{g}$ in the $11 \mathrm{Bi}$-dosed ducks, and the means (sexes combined) were $0.310 \mu \mathrm{g} / \mathrm{g}$ for 100 -dosed birds and $0.157 \mu \mathrm{g} / \mathrm{g}$ for $11 \mathrm{Bi}$-dosed ducks. We found no differences among doses or between sexes (doses combined) in the mean concentrations of $\mathrm{Pb}$ in the liver (Table 10).

The MDL for $\mathrm{Sn}$ in the liver was $12.8 \mu \mathrm{g} / \mathrm{g}$. All but 3 of 120 livers had <MDL of $\mathrm{Sn}$. These three livers had $13.1 \mu \mathrm{g} / \mathrm{g} \mathrm{Sn}$ in an Fe-dosed duck, $13.2 \mu \mathrm{g} / \mathrm{g}$ in a 0 -dosed duck, and $18.8 \mu \mathrm{g} / \mathrm{g}$ in a Bidosed duck. 
Table 5. Mean weight of kidneys and mean percentage they contributed to total body weight in game-farm mallards 30 days after dosing with 0 shot; six, No. 4, Fe shot; or six, No. 4, Bi shot ( $n=20$ females and 20 males in each group).

\begin{tabular}{llll}
\hline Sex & Dose & $\begin{array}{l}\text { Mean } \\
\text { Weight }(\mathrm{g})\end{array}$ & $\begin{array}{l}\text { Mean \% of } \\
\text { body wt }\end{array}$ \\
\hline $\mathrm{F}$ & 0 & 6.5 & 0.6 \\
$\mathrm{M}$ & & $0.27^{\mathrm{a}}$ & 0.02 \\
& 0 & 6.6 & 0.5 \\
$\mathrm{~F}$ & $\mathrm{Fe}$ & 0.23 & 0.02 \\
& & 6.4 & 0.6 \\
$\mathrm{M}$ & $\mathrm{Fe}$ & 0.27 & 0.02 \\
$\mathrm{~F}$ & $\mathrm{Fi}$ & 6.5 & 0.5 \\
& $\mathrm{Bi}$ & 0.14 & 0.01 \\
$\mathrm{M}$ & $\mathrm{Bi}$ & 0.4 & 0.6 \\
& $\mathrm{Bi}$ & 6.4 & 0.02 \\
& & 0.22 & 0.5 \\
\end{tabular}

a SE.

Difference among doses in weight of kidneys:

$$
F_{2,14}=0.22 ; P=0.8006 \text {. }
$$

Difference between sexes in percentage kidneys contrib-

uted to total body weight: $F_{1,114}=33.91 ; P<0.00001$.

Difference among doses in percentage kidneys contrib-

uted to total body weight: $F_{2,114}=0.13 ; P=0.8756$.

Table 6. Mean weight of gonads and mean percentage they contributed to total body weight in game-farm mallards 30 days after dosing with 0 shot; six, No. 4, Fe shot; or six, No. 4, Bi shot ( $\mathrm{n}=20$ females and 20 males in each group).

\begin{tabular}{llll}
\hline Sex & Dose & $\begin{array}{l}\text { Mean } \\
\text { Weight }(\mathrm{g})\end{array}$ & $\begin{array}{l}\text { Mean \% of } \\
\text { body wt }\end{array}$ \\
\hline $\mathrm{F}$ & 0 & 6.4 & 0.6 \\
$\mathrm{M}$ & & $1.84^{\mathrm{a}}$ & 0.18 \\
& 0 & 26.4 & 2.2 \\
$\mathrm{~F}$ & $\mathrm{Fe}$ & 1.02 & 0.25 \\
& & 10.1 & 0.9 \\
$\mathrm{M}$ & $\mathrm{Fe}$ & 0.25 \\
& $\mathrm{Fe}$ & 28.0 & 2.4 \\
$\mathrm{~F}$ & $\mathrm{~F}$ & 3.23 & 0.29 \\
& $\mathrm{Bi}$ & 4.3 & 0.4 \\
$\mathrm{M}$ & $\mathrm{Bi}$ & 2.46 & 0.13 \\
& $\mathrm{Bi}$ & 2.5 & 2.0 \\
& & & 0.19 \\
\hline
\end{tabular}

a SE.

Difference between sexes in weight of gonads:

$$
F_{1,14}=83.04 ; P<0.00001 \text {. }
$$

Difference among doses in weight of gonads:

$$
F_{2,14}=2.54 ; P=0.0830 \text {. }
$$

Difference between sexes in the percentage gonads contributed to total body weight:

$$
F_{1,114}=67.57 ; P<0.00001 \text {. }
$$

Difference among doses in the percentage gonads contributed to total body weight:

$$
F_{2,114}=2.47 ; P=0.0889 \text {. }
$$


Table 7. Mean hematocrit (Hct) on Days $0^{a}, 15$, and $30^{b}$ of game-farm mallards each dosed with 0 shot; six, No. 4 , Fe shot; or six, No. 4, Bi shot and percentage change in Hct from Day 0 to Day 30 ( $n=20$ females and 20 males in each group).

\begin{tabular}{|c|c|c|c|c|c|}
\hline \multirow[b]{2}{*}{ Sex } & \multirow[b]{2}{*}{ Dose } & \multicolumn{3}{|c|}{ Mean Hct } & \multirow{2}{*}{$\begin{array}{c}\text { Mean \% change } \\
\text { in Hct-Day } 0 \\
\text { to Day } 30\end{array}$} \\
\hline & & Day 0 & Day 15 & Day 30 & \\
\hline \multirow[t]{2}{*}{$\mathrm{F}+\mathrm{M}$} & 0 & 46.7 & 48.2 & 49.6 & +6.6 \\
\hline & & $0.49^{c}$ & 0.41 & 0.48 & 1.25 \\
\hline \multirow[t]{2}{*}{$\mathrm{F}+\mathrm{M}$} & $\mathrm{Fe}$ & 45.8 & 49.7 & 50.8 & +12.8 \\
\hline & & 0.90 & 0.58 & 0.55 & 2.49 \\
\hline \multirow[t]{2}{*}{$\mathrm{F}+\mathrm{M}$} & $\mathrm{Bi}$ & 45.7 & 48.7 & 49.7 & +11.8 \\
\hline & & 0.98 & 0.47 & 0.52 & 3.92 \\
\hline
\end{tabular}

a Ducks were dosed on Day 0.

b Ducks were killed on Day 30.

c SE.

Difference among doses: $\quad F_{2,117}=0.71 ; P=0.4961$.

Change over time: $\quad F_{2,234}=50.10 ; P<0.00001$.

Table 8. Mean concentrations ( $\mu \mathrm{g} / \mathrm{g}$ wet $w \mathrm{t}$ ) of $\mathrm{Bi}$ and $\mathrm{Pb}$ in kidneys of game-farm mallards 30 days after dosing with 0 shot (controls) compared with ducks dosed with six, No. 4, Bi shot, as measured by GFAA.

\begin{tabular}{cccc}
\hline & & \multicolumn{2}{c}{ Dose } \\
\cline { 3 - 4 } Element & Sex & $0^{\mathrm{a}}$ & $\mathrm{Bi}^{\mathrm{b}}$ \\
\hline $\mathrm{Bi}$ & $\mathrm{F}$ & 0.140 & 8.05 \\
& $\mathrm{M}$ & $0.000^{\mathrm{c}}$ & 1.14 \\
& & 0.528 & 4.77 \\
& $\mathrm{~F} \& \mathrm{M}$ & 0.058 & 1.45 \\
$\mathrm{~Pb}$ & $\mathrm{~F}$ & 0.334 & 6.86 \\
& & 0.070 & 0.99 \\
& $\mathrm{M}$ & 0.138 & 0.427 \\
& & 0.070 & 0.179 \\
& $\mathrm{~F} \& \mathrm{M}$ & 0.742 & 0.112 \\
& & 0.640 & 0.033 \\
& & 0.440 & 0.313 \\
\end{tabular}

MDL $=$ Method Detection Limit $(\mu \mathrm{g} / \mathrm{g}$ wet $w \mathrm{t}$ ) by GFAA for Bi in kidneys $=0.10 \mu \mathrm{g} / \mathrm{g}$ for 10 ducks and $0.27 \mu \mathrm{g} / \mathrm{g}$ for 11 ducks and $\mathrm{Pb}=0.27 \mu \mathrm{g} / \mathrm{g}$ for 10 ducks and $0.15 \mu \mathrm{g} / \mathrm{g}$ for 11 ducks.

a $\mathrm{N}=10$.

b $N=11$.

c $\mathrm{SE}$.

$\mathrm{Bi}$

Difference between sexes in Bi-dosed ducks:

$$
F_{1,9}=3.09 ; P=0.1127 \text {. }
$$

Difference between doses:

$$
F_{1,10}=43.32 ; P=0.0001 \text {. }
$$

$\mathrm{Pb}$

Difference between sexes in 0-dosed ducks:

$$
F_{1,4}=0.88 ; P=0.4011 \text {. }
$$

Difference between sexes in Bi-dosed ducks:

$$
F_{1,9}=1.68 ; P=0.2274 \text {. }
$$

Difference between doses:

$$
F_{1,19}=0.15 ; P=0.7035 \text {. }
$$


Table 9. Mean concentrations ( $\mu \mathrm{g} / \mathrm{g}$ wet wt) of $\mathrm{Cu}, \mathrm{P}, \mathrm{Fe}, \mathrm{Ca}, \mathrm{Mg}$, and $\mathrm{Zn}$ (by ICP) in kidneys of game farmmallards 30 days after dosing with 0 shot (controls) compa-red with ducks dosed with six, No. 4, Fe shot or six, No. 4, Bi shot $(n=20$ females and 20 males in each group).

\begin{tabular}{|c|c|c|c|c|}
\hline \multirow[b]{2}{*}{ Element } & \multirow[b]{2}{*}{ Sex } & \multicolumn{3}{|c|}{ Dose } \\
\hline & & 0 & $\mathrm{Fe}$ & $\mathrm{Bi}$ \\
\hline \multirow[t]{6}{*}{$\mathrm{Cu}$} & $\mathrm{F}$ & 5.50 & 5.34 & 5.74 \\
\hline & & $0.38^{a}$ & 0.26 & 0.49 \\
\hline & M & 7.13 & 9.08 & 6.60 \\
\hline & & 0.45 & 3.37 & 0.65 \\
\hline & $F \& M$ & 6.31 & 7.31 & 6.14 \\
\hline & & 0.34 & 1.79 & 0.40 \\
\hline \multirow[t]{6}{*}{$\mathrm{P}$} & $\mathrm{F}$ & 2758 & 2937 & 3050 \\
\hline & & 53 & 80 & 67 \\
\hline & M & 3167 & 2903 & 3006 \\
\hline & & 203 & 30 & 48 \\
\hline & $\mathrm{F} \& \mathrm{M}$ & 2962 & 2919 & 3030 \\
\hline & & 112 & 40 & 42 \\
\hline \multirow[t]{6}{*}{$\mathrm{Fe}$} & $\mathrm{F}$ & 110 & 152 & 118 \\
\hline & & 6.0 & 8.5 & 8.4 \\
\hline & M & 136 & 139 & 129 \\
\hline & & 7.5 & 8.2 & 8.1 \\
\hline & $F \& M$ & 123 & 145 & 123 \\
\hline & & 5.6 & 6.0 & 5.8 \\
\hline \multirow[t]{6}{*}{$\mathrm{Ca}$} & $\mathrm{F}$ & 84.0 & 84.4 & 87.2 \\
\hline & & 7.1 & 5.3 & 4.5 \\
\hline & M & 79.9 & 70.2 & 72.2 \\
\hline & & 7.3 & 1.8 & 1.6 \\
\hline & $F \& M$ & 81.9 & 76.9 & 80.4 \\
\hline & & 5.0 & 3.1 & 3.0 \\
\hline \multirow[t]{6}{*}{$\mathrm{Mg}$} & $\mathrm{F}$ & 196 & 199 & 206 \\
\hline & & 3.5 & 4.2 & 3.8 \\
\hline & M & 216 & 197 & 204 \\
\hline & & 14.8 & 2.4 & 3.7 \\
\hline & $F \& M$ & 206 & 198 & 205 \\
\hline & & 7.7 & 2.3 & 2.6 \\
\hline \multirow[t]{6}{*}{$\mathrm{Zn}$} & $\mathrm{F}$ & 25.3 & 24.7 & 27.4 \\
\hline & & 0.8 & 0.6 & 1.2 \\
\hline & M & 27.9 & 25.6 & 29.3 \\
\hline & & 1.5 & 0.8 & 1.1 \\
\hline & $\mathrm{F} \& \mathrm{M}$ & 26.6 & 25.2 & 28.2 \\
\hline & & 0.9 & 0.5 & 0.8 \\
\hline
\end{tabular}

a SE.

$\mathrm{Cu}$

Difference among doses:

P

Difference among doses:

$F_{2,57}=0.32 ; P=0.7280$.

$F_{2.55}=0.63 ; P=0.5384$

Interaction between sex and dose:

$F_{2,17}=3.48 ; P=0.0540$.

$\mathrm{Fe}$

Difference among doses: $\quad F_{2,55}=4.98 ; P=0.0103$.

Interaction between sex and dose: $F_{2,55}=3.01$;

Difference between 0 -dosed and

Fe-dosed ducks:

$P=0.0574$.

Difference between 0-dosed and

Bi-dosed ducks:

Difference between Fe-dosed and

Bi-dosed ducks:
$P<0.05$.

$P>0.10$.

$P<0.05$.
Ca

Difference between sexes: $F_{1,55}=6.99 ; P=0.0107$.

Difference among doses: $F_{2,33}=0.41 ; P=0.6680$.

$\mathrm{Mg}$

Difference among doses: $F_{255}=0.80 ; P=0.4536$

$\mathrm{Zn}$

Difference between sexes: $F_{1,55}=4.45 ; P=0.0395$.

Difference among doses: $F_{2.55}=4.56 ; P=0.0147$.

Difference between Fe-dosed and

Bi-dosed ducks: $\quad P<0.05$. 
Table 10. Mean concentrations ( $\mu \mathrm{g} / \mathrm{g}$ wet wt) of $\mathrm{Bi}$ and $\mathrm{Pb}$ in livers of game-farm mallards 30 days after dosing with 0 shot (controls) compared with ducks dosed with six, No. 4 Bi, shot (analyses by GFAA).

\begin{tabular}{cccc}
\hline & & \multicolumn{2}{c}{ Dose } \\
\cline { 3 - 4 } Element & Sex & 0 & Bi \\
\hline $\mathrm{Bi}$ & $\mathrm{F}$ & $0.140^{\mathrm{a}}$ & $2.79^{\mathrm{c}}$ \\
& & $0.000^{\mathrm{b}}$ & 0.675 \\
& $\mathrm{M}$ & $0.246^{\mathrm{d}}$ & $1.25^{\mathrm{e}}$ \\
& $\mathrm{F} \& \mathrm{M}$ & 0.033 & 0.347 \\
$\mathrm{~Pb}$ & $\mathrm{~F}$ & 0.193 & 2.23 \\
& & 0.024 & 0.492 \\
& $\mathrm{M}$ & 0.068 & 0.184 \\
& & 0.018 & 0.053 \\
& & 0.552 & 0.110 \\
& $\mathrm{~F} \& \mathrm{M}$ & 0.376 & 0.030 \\
& & 0.310 & 0.157 \\
\hline
\end{tabular}

$\mathrm{MDL}=$ Method Detection Limit $(\mu \mathrm{g} / \mathrm{g}$ wet $w \mathrm{t})$ by GFAA for $\mathrm{Bi}=0.27$ for 10 ducks and 0.10 for 11 ducks and for $\mathrm{Pb}=0.10$ for 10 ducks and 0.15 for 11 ducks.

$$
\begin{aligned}
& \mathrm{N}=5 . \\
& \text { bE. } \\
& \text { c } \mathrm{N}=7 . \\
& \text { d } \mathrm{N}=5 . \\
& \text { e } \mathrm{N}=4 .
\end{aligned}
$$

$\mathrm{Bi}$

Difference between doses: $\mathrm{F}_{1,10}=17.14 ; P=0.0020$.

$\mathrm{Pb}$

Difference between doses: $\mathrm{F}_{1,19}=0.65 ; P=0.4294$.

\section{continued from page 195}

The mean concentration of $\mathrm{Cu}$ in the livers of 0 -dosed females was $85.5 \mu \mathrm{g} / \mathrm{g}$ versus $191 \mu \mathrm{g} / \mathrm{g}$ in males, $56.3 \mu \mathrm{g} / \mathrm{g}$ in the livers of Fe-dosed females versus $172 \mu \mathrm{g} / \mathrm{g}$ in males, and $78.3 \mu \mathrm{g} / \mathrm{g}$ in the livers of Bi-dosed females versus $149 \mu \mathrm{g} / \mathrm{g}$ in males (Table 11, Figure 1). Males had higher mean concentrations of $\mathrm{Cu}$ in the liver than females, but we found no differences among doses in the mean concentration of $\mathrm{Cu}$ in the livers.

Females consistently had more $P$ in their livers than males (Table 11): 0-dosed, 3,164 $\mu \mathrm{g} / \mathrm{g}$ in females versus 2,998 P $\mu \mathrm{g} / \mathrm{g}$ in males; Fe-dosed, $3,258 \mu \mathrm{g} / \mathrm{g}$ in females versus $2,958 \mu \mathrm{g} / \mathrm{g}$ in males; and Bi-dosed, 3,154 $\mu \mathrm{g} / \mathrm{g}$ in females versus 2,897 $\mu \mathrm{g} / \mathrm{g}$ in males. We found no differences among doses in the mean concentrations of $\mathrm{P}$ in the livers (Table 11).

We detected no difference between sexes in the mean concentrations of Fe in the livers, but the mean concentrations of Fe differed among doses: $411 \mu \mathrm{g} / \mathrm{g}$ in 0 -dosed ducks versus $1086 \mu \mathrm{g} / \mathrm{g}$ in Fe-dosed ducks versus $399 \mu \mathrm{g} / \mathrm{g}$ in Bi-dosed ducks, sexes combined. Differences were detected in the mean concentrations of Fe in 0-dosed versus Fedosed ducks and in Fe-dosed versus Bi-dosed, but not in 0-dosed versus Bi-dosed ducks (Table 11).

The mean concentrations of $\mathrm{Ca}$ in livers did not differ between sexes, but with sexes combined, the mean concentrations of $\mathrm{Ca}$ in the liver were different among doses. The mean concentration of $\mathrm{Ca}$ in the livers was higher in 0-dosed ducks $(62.8 \mu \mathrm{g} / \mathrm{g})$ than in Fe-dosed ducks $(50.4$ $\mu \mathrm{g} / \mathrm{g})$, but was not higher in 0-dosed than in Bidosed ducks $(51.4 \mu \mathrm{g} / \mathrm{g}$ ) (Table 11). We detected no difference in the mean concentrations of $\mathrm{Ca}$ in the livers of Fe-dosed and Bi-dosed ducks.

The mean concentration of $\mathrm{Mg}$ in the livers ranged from $211 \mu \mathrm{g} / \mathrm{g}$ in 0 -dosed males to $224 \mu \mathrm{g} /$ $\mathrm{g}$ in Fe-dosed females, but no difference existed between sexes. With sexes combined, no differences were detected among doses in the mean concentrations of $\mathrm{Mg}$ in the livers: 0 -dosed ducks, $213 \mu \mathrm{g} / \mathrm{g}$; Fe-dosed ducks, $219 \mathrm{mg} / \mathrm{g}$; and Bidosed ducks, $214 \mu \mathrm{g} / \mathrm{g}$ (Table 11).

Continued on page 202 
Table 11. Mean concentrations ( $\mu \mathrm{g} / \mathrm{g}$ wet wt) of $\mathrm{Cu}, \mathrm{P}, \mathrm{Fe}, \mathrm{Ca}, \mathrm{Mg}$, and $\mathrm{Zn}$ (by ICP) in livers of game-farm mallards 30 days after dosing with 0 shot (controls) compared with ducks dosed with six, No. 4, Fe shot or six, No. 4, Bi shot $(\mathrm{n}=20$ for each sex).

\begin{tabular}{|c|c|c|c|c|}
\hline \multirow[b]{2}{*}{ Element } & \multirow[b]{2}{*}{ Sex } & \multicolumn{3}{|c|}{ Dose } \\
\hline & & 0 & $\mathrm{Fe}$ & $\mathrm{Bi}$ \\
\hline \multirow[t]{6}{*}{$\mathrm{Cu}$} & $\mathrm{F}$ & 85.5 & 56.3 & 78.3 \\
\hline & & $16.4^{\mathrm{a}}$ & 12.1 & 15.6 \\
\hline & M & 191 & 172 & 149 \\
\hline & & 37.6 & 31.8 & 32.6 \\
\hline & $F \& M$ & 138 & 114 & 114 \\
\hline & & 21.9 & 19.2 & 18.7 \\
\hline \multirow[t]{6}{*}{ P } & F & 3164 & 3258 & 3154 \\
\hline & & 126 & 77 & 93 \\
\hline & M & 2998 & 2958 & 2897 \\
\hline & & 71 & 88 & 63 \\
\hline & F \& M & 3081 & 3108 & 3026 \\
\hline & & 72 & 62 & 59 \\
\hline \multirow[t]{6}{*}{$\mathrm{Fe}$} & F & 416 & 1158 & 435 \\
\hline & & 37.8 & 91 & 43.6 \\
\hline & M & 406 & 1015 & 362 \\
\hline & & 58.8 & 111 & 24.9 \\
\hline & F\& M & 411 & 1086 & 399 \\
\hline & & 34.1 & 72 & 161.0 \\
\hline \multirow[t]{6}{*}{$\mathrm{Ca}$} & $\mathrm{F}$ & 66.4 & 54.0 & 52.9 \\
\hline & & 7.0 & 2.5 & 3.6 \\
\hline & M & 59.2 & 46.8 & 49.8 \\
\hline & & 7.9 & 3.8 & 4.6 \\
\hline & $F \& M$ & 62.8 & 50.4 & 51.4 \\
\hline & & 5.3 & 2.3 & 2.9 \\
\hline \multirow[t]{6}{*}{$\mathrm{Mg}$} & $\mathrm{F}$ & 215 & 224 & 216 \\
\hline & & 8.4 & 4.6 & 4.5 \\
\hline & M & 211 & 214 & 212 \\
\hline & & 4.9 & 6.5 & 5.0 \\
\hline & F \& M & 213 & 219 & 214 \\
\hline & & 4.8 & 4.0 & 3.2 \\
\hline \multirow[t]{6}{*}{$\mathrm{Zn}$} & $\mathrm{F}$ & 53.3 & 48.4 & 50.8 \\
\hline & & 3.5 & 2.6 & 3.2 \\
\hline & M & 48.9 & 48.1 & 45.4 \\
\hline & & 2.8 & 2.8 & 1.9 \\
\hline & $F \& M$ & 51.1 & 48.2 & 48.1 \\
\hline & & 2.2 & 1.9 & 1.9 \\
\hline
\end{tabular}

a SE.

ifference between sexes:

ifference among doses:

$$
\begin{aligned}
& F_{1,76}=20.64 ; \quad P<0.00001 . \\
& F_{2,76}=0.56 ; \quad P=0.5721 .
\end{aligned}
$$

ifference between Fe-dosed females and Fe-dosed males ifference between 0 -dosed females and 0-dosed males ifference between Bi-dosed females and 0-dosed males:

$$
\begin{aligned}
& F_{1,114}=11.07 ; P=0.0012 . \\
& F_{2,114}=0.45 ; P=0.6380 . \\
& F_{2,117}=67.53 ; P<0.00001 .
\end{aligned}
$$

Ca Difference among doses: $\quad F_{2117}=3.43 ; P=0.0356$.

Difference between 0-dosed and Fe-dosed; $\quad P<0.05$. Difference between 0-dosed and Bi dosed; $\quad P>0.05$. Difference between Fe-dosed and Bi dosed; $P>0.10$. $\mathrm{Mg}$

Difference among doses: $\quad F_{2.117}=0.66 ; P=0.5182$.

$\mathrm{Zn}$ Sn

$$
\text { Difference among doses: } \quad F_{2,117}=0.70 ; \quad P=0.5005 \text {. }
$$

The mean level was $<$ MDL: $=12.8 \mathrm{ppm}$.

ifference between 0 -dosed and Fe-dosed; $P<0.01$.

ifference between 0 -dosed and Bi-dosed; $P>0.10$. ifference between Fe-dosed and Bi-dosed; $P<0.01$. 


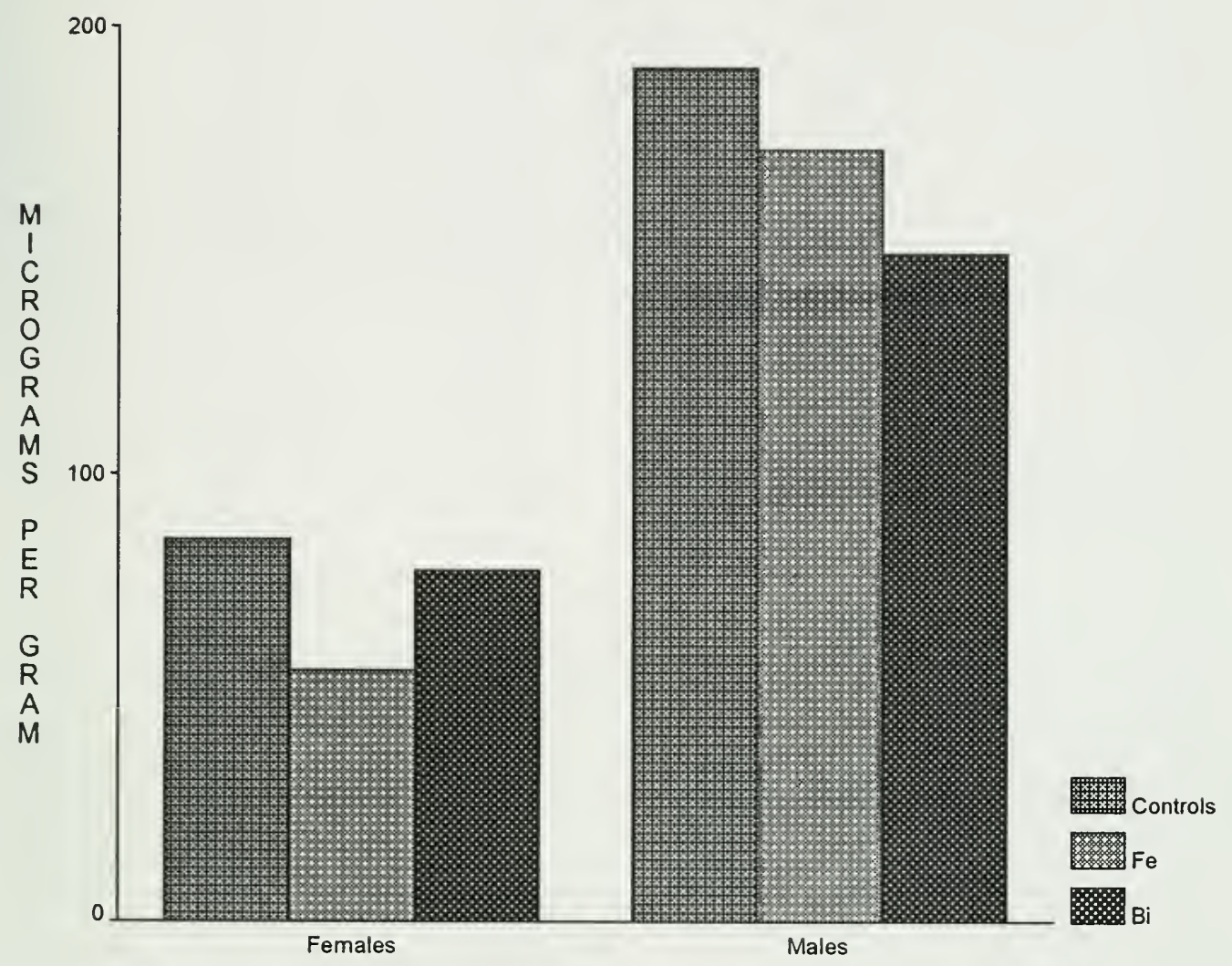

Figure 1. Mean concentrations of copper ( $\mu \mathrm{g} / \mathrm{g}$ wet weight) in liver of game-farm mallards 30 days after dosing with $0 ; 6$, No. 4, steel (iron); or 6, No. 4, bismuth shot. 
Table 12. Mean concentrations ( $\mu / \mathrm{g}$ wet $w \mathrm{t}$ ) of $\mathrm{Bi}$ and $\mathrm{Pb}$ in gonads of game-farm mallards 30 days after dosing with 0 shot (controls) compared with ducks dosed with six, No. 4, Bi shot (by GFAA Furnace).

\begin{tabular}{cccc}
\hline & & \multicolumn{2}{c}{ Dose } \\
\cline { 3 - 4 } Element & Sex & $0^{\mathrm{a}}$ & $\mathrm{Bi}^{\mathrm{a}}$ \\
\hline $\mathrm{Bi}$ & $\mathrm{F}$ & 0.050 & 0.677 \\
& $\mathrm{M}$ & $0.000^{\mathrm{b}}$ & 0.455 \\
& $\mathrm{~F} \& \mathrm{M}$ & 0.050 & 0.155 \\
& & 0.000 & 0.048 \\
$\mathrm{Fb}$ & $\mathrm{F}$ & 0.050 & 0.468 \\
& & 0.000 & 0.277 \\
& $\mathrm{M}$ & 0.080 & 0.093 \\
& & 0.000 & 0.013 \\
& $\mathrm{~F} \& \mathrm{M}$ & 0.080 & 0.100 \\
& & 0.000 & 0.020 \\
& 0.080 & 0.096 \\
\end{tabular}

$\mathrm{MDL}=$ Method Detection Limit for gonads $(\mu \mathrm{g} / \mathrm{g}$ wet $w \mathrm{t})$

a $\mathrm{N}=20$.

by $\mathrm{GFAA}=0.15$ for $\mathrm{Pb}$ and 0.10 for $\mathrm{Bi}$.

b $S E$.

$\mathrm{Bi}$

Difference between 0-dosed males and Bi-dosed females:

$\mathrm{F}_{1,7}=6.2821 ; P=0.0406$.

continued from page 199

The mean concentration of $\mathrm{Zn}$ in the livers ranged from $45.4 \mu \mathrm{g} / \mathrm{g}$ for Bi-dosed males to 53.3 $\mu \mathrm{g} / \mathrm{g}$ for 0 -dosed females, and values were not different between sexes. With sexes combined, no differences were found among the mean concentrations of $\mathrm{Zn}$ in livers of 0 -dosed ducks, $51.1 \mu \mathrm{g} /$ g; Fe-dosed ducks, $48.2 \mu \mathrm{g} / \mathrm{g}$; and Bi-dosed ducks, $48.1 \mu \mathrm{g} / \mathrm{g}$ (Table 11).

\section{Gonads}

The MDL for Bi in gonads by ICP was $12.0 \mu \mathrm{g} / \mathrm{g}$ for 33 ducks and $13.2 \mu \mathrm{g} / \mathrm{g}$ for 28 ducks. All but five values for $B i$ in gonads were $<M D L$. The concentration of $\mathrm{Bi}$ in the five gonads with concentrations $>$ MDL ranged from 15.2 to $27.8 \mu \mathrm{g} / \mathrm{g}$ and averaged $19.9 \mu \mathrm{g} / \mathrm{g}$.

As determined by GFAA Furnace, the concentrations of $B i$ in gonads of 0 -dosed ducks were all $<$ MDL $(0.10 \mu \mathrm{g} / \mathrm{g})$. All Bi-dosed ducks had a mean of $0.468 \mu \mathrm{g} / \mathrm{g}$ Bi in their gonads compared with $<$ MDL in 0-dosed ducks (Table 12).

The MDL for $\mathrm{Pb}$ in the gonads by ICP was $7.10 \mu \mathrm{g} / \mathrm{g}$ (wet wt) for 33 ducks and $7.75 \mu \mathrm{g} / \mathrm{g}$ for 28 ducks. Only one $(11.8 \mu \mathrm{g} / \mathrm{g})$ mean concentration of $\mathrm{Pb}$ in the gonads was $>\mathrm{MDL}$. The mean concentrations of $\mathrm{Pb}$, as determined by GFAA furnace, in gonads of 0 -dosed and Bi-dosed ducks were all <MDL $(0.15 \mu \mathrm{g} / \mathrm{g})$ (Table 12).

The MDL for $\mathrm{Sn}$ in the gonads by ICP was $15.5 \mu \mathrm{g} / \mathrm{g}$ (wet wt). Only one female had > MDL $(17.8 \mu \mathrm{g} / \mathrm{g})$ of $\mathrm{Sn}$ in the liver. Mean concentrations of $\mathrm{Cu}$ in the gonads differed by sex in 0-dosed ducks, but not in Fe-dosed and Bi-dosed ducks. With doses combined, mean concentrations of $\mathrm{Cu}$ differed by sex with males having lower concentrations than females (Table 13). No differences were found for the mean concentrations of $\mathrm{Cu}$ in the gonads of mallards among doses.

Mean concentrations of $P$ in the gonads were not different by sex within doses. With sexes combined, no difference was detected in the concentrations of $\mathrm{P}$ in the gonads among doses (Table 13).

Differences in the mean concentrations of $\mathrm{Fe}$ in the gonads of males and females were substantial (Figure 2) in all dosed groups: 0-dosed, 56.4 $\mu \mathrm{g} / \mathrm{g}$ in females versus $12.5 \mu \mathrm{g} / \mathrm{g}$ in males; Fedosed, $53.5 \mu \mathrm{g} / \mathrm{g}$ in females versus $10.7 \mu \mathrm{g} / \mathrm{g}$ in males; and Bi-dosed, $40.3 \mu \mathrm{g} / \mathrm{g}$ in females versus $16.8 \mu \mathrm{g} / \mathrm{g}$ in males. Mean concentrations of Fe in the gonads of ducks within doses were not different (Table 13).

Females contained up to 17 times more Ca in their gonads than males (Figure 3): 0-dosed 
Table 13. Mean concentrations ( $\mu \mathrm{g} / \mathrm{g}$ wet wt) of $\mathrm{Cu}, \mathrm{P}, \mathrm{Fe}, \mathrm{Ca}, \mathrm{Mg}$, and $\mathrm{Zn}$ in gonads of game-farm mallards 30 days after dosing with 0 shot (controls) compared with ducks dosed with six, No. 4, Fe shot or six, No. 4, Bi shot (N=10, 11 , or 12 for each sex).

\begin{tabular}{|c|c|c|c|c|}
\hline \multirow[b]{2}{*}{ Element } & \multirow[b]{2}{*}{ Sex } & \multicolumn{3}{|c|}{ Dose } \\
\hline & & 0 & $\mathrm{Fe}$ & $\mathrm{Bi}$ \\
\hline \multirow[t]{6}{*}{$\mathrm{Cu}$} & $F$ & 1.76 & 1.70 & 1.48 \\
\hline & & $0.215^{\mathrm{a}}$ & 0.152 & 0.183 \\
\hline & $\mathbf{M}$ & 0.985 & 1.12 & 1.34 \\
\hline & & 0.149 & 0.113 & 0.174 \\
\hline & $F \& M$ & 1.37 & 1.41 & 1.41 \\
\hline & & 0.155 & 0.114 & 0.125 \\
\hline \multirow[t]{6}{*}{$\mathrm{P}$} & $\mathrm{F}$ & 3132 & 3102 & 2566 \\
\hline & & 388 & 395 & 342 \\
\hline & M & 2662 & 2717 & 2917 \\
\hline & & 41 & 91 & 128 \\
\hline & $F \& M$ & 2897 & 2910 & 2726 \\
\hline & & 197 & 202 & 195 \\
\hline \multirow[t]{6}{*}{$\mathrm{Fe}$} & $F$ & 56.4 & 53.5 & 40.3 \\
\hline & & 7.5 & 8.0 & 5.4 \\
\hline & M & 12.5 & 10.7 & 16.8 \\
\hline & & 2.8 & 1.2 & 5.4 \\
\hline & $F \& M$ & 34.4 & 32.1 & 29.1 \\
\hline & & 6.4 & 6.3 & 4.6 \\
\hline \multirow[t]{6}{*}{$\mathrm{Ca}$} & $F$ & 540.0 & 590.1 & 334.4 \\
\hline & & 165.4 & 179.2 & 102.5 \\
\hline & M & 34.5 & 34.4 & 139.6 \\
\hline & & 1.7 & 1.6 & 104.5 \\
\hline & $F \& M$ & 287.2 & 312.2 & 241.7 \\
\hline & & 99.2 & 108.0 & 74.6 \\
\hline \multirow[t]{6}{*}{$\mathrm{Mg}$} & $\mathrm{F}$ & 113 & 127 & 126 \\
\hline & & 15.9 & 14.6 & 16.2 \\
\hline & $\mathrm{M}$ & 203 & 206 & 201 \\
\hline & & 2.5 & 6.3 & 11.8 \\
\hline & $F \& M$ & 158 & 166 & 162 \\
\hline & & 13.0 & 11.9 & 13.0 \\
\hline \multirow[t]{6}{*}{$\mathrm{Zn}$} & $\mathrm{F}$ & 23.7 & 24.6 & 19.3 \\
\hline & & 4.0 & 3.6 & 2.9 \\
\hline & M & 13.9 & 14.3 & 16.4 \\
\hline & & 0.4 & 0.6 & 2.0 \\
\hline & $F \& M$ & 18.8 & 19.4 & 18.0 \\
\hline & & 2.2 & 2.1 & 1.8 \\
\hline
\end{tabular}

SE.

$\mathrm{Cu}$

Difference between sexes: $\quad F_{1,55}=13.20 ; P=0.0006$.

Difference between sexes in 0-dosed ducks: $\quad P<0.05$.

Difference among doses: $\quad F_{2,55}=0.03 ; P=0.9664$.

$P$

Difference among doses: $\quad F_{2,56}=0.23 ; P=0.7965$.

Fe

Difference between sexes: $\quad F_{1,35}=64.51 ; P=0.00001$.

Difference between sexes in 0 -dosed ducks: $\quad P<0.01$.

Difference between sexes in Fe-dosed ducks: $P<0.01$.

Difference between sexes in Bi-dosed ducks: $P<0.05$.

Difference among doses:

$$
F_{2,55}=0.57 ; P=0.5704
$$

Ca

Difference between sexes: $\quad F_{1,29}=19.50 ; P<0.00001$.

Difference among doses:

$F_{2,55}=0.22 ; P=0.8021$.

$\mathrm{Mg}$

Difference between sexes: $\quad F_{1,39}=65.70 ; P<0.00001$.

Difference among doses: $\quad F_{2,55}=0.22 ; P=0.8051$.

$\mathrm{Zn}$

Difference between sexes: $\quad F_{1,31}=12.66 ; P=0.0012$.

Difference among doses: $\quad F_{2,56}=0.17 ; P=0.8402$.
0.183

.174

0.125

566

2917

28

95

5.4

5.4

29.1

334.4

102.5

104.5

241.7

26

6.2

1.8

62

9.3

.9

.0

8.0 
continued from page 202

females $(540.0 \mathrm{mg} / \mathrm{g}$ ) versus 0-dosed males (34.5 $\mathrm{mg} / \mathrm{g}$ ); Fe-dosed females $(590.1 \mathrm{mg} / \mathrm{g}$ ) versus Fedosed males $(34.4 \mathrm{mg} / \mathrm{g})$; and Bi-dosed females (334.4 mg/g) versus Bi-dosed males $(139.6 \mathrm{mg} /$ g). With doses combined, females also contained higher mean concentrations of $\mathrm{Ca}$ in their gonads than males. No differences existed, however, in the mean concentrations of $\mathrm{Ca}$ in the gonads among doses within each sex (Table 13).

Males had higher mean concentrations of $\mathrm{Mg}$ in their gonads than females (Table 13), but no differences were detected among doses within each sex. With doses combined, females had higher mean concentrations of $\mathrm{Zn}$ in their gonads than males (Table 13). With sexes combined, $\mathrm{Zn}$ values in gonads varied little among doses.

\section{Plasma and Blood Cells}

The MDLs (by ICP) for Bi in plasma were $7.38 \mu \mathrm{g}$ / $\mathrm{g}$ (wet wt) for Day 0,21.8 $\mu \mathrm{g} / \mathrm{g}$ for Day 15 , and 11.8 $\mu \mathrm{g} / \mathrm{g}$ for Day 30. The MDLs for Bi in blood cells were $8.72 \mu \mathrm{g} / \mathrm{g}$ for Day 0, $9.35 \mu \mathrm{g} / \mathrm{g}$ for Day 15, and $16.3 \mu \mathrm{g} / \mathrm{g}$ for Day 30. All mean levels were $<$ MDLs for Bi in plasma and blood cells. After the analyses were completed by ICP, the amounts of plasma and blood cells remaining were insufficient to analyze for Bi by GFAA.

The MDLs for $\mathrm{Pb}$ in the plasma were $2.20 \mu \mathrm{g} /$ $\mathrm{g}$ for Day $0,4.42 \mu \mathrm{g} / \mathrm{g}$ for Day 15 , and $3.34 \mu \mathrm{g} / \mathrm{g}$ for Day 30. MDLs for Pb in blood cells were $2.78 \mu \mathrm{g} /$ $\mathrm{g}$ for Day $0,2.68 \mu \mathrm{g} / \mathrm{g}$ for Day 15, and 4.69 for Day 30. All of the mean values for $\mathrm{Pb}$ concentrations in the plasma and in the cells were $<$ MDLs.

The MDLs for $S n$ in the plasma were $5.81 \mu \mathrm{g} /$ $\mathrm{g}$ for Day $0,7.96 \mu \mathrm{g} / \mathrm{g}$ for Day 15 , and $10.2 \mu \mathrm{g} / \mathrm{g}$ for Day 30. The MDLs for Sn in blood cells were 8.06 $\mu \mathrm{g} / \mathrm{g}$ for Day 0, 5.75 for Day 15, and 6.37 for Day 30. All mean concentrations of $\mathrm{Sn}$ in plasma and cells were $<$ MDLs on all three days.

The MDLs for $\mathrm{Cu}$ in plasma were $0.17 \mu \mathrm{g} / \mathrm{g}$ for Day $0,0.483 \mu \mathrm{g} / \mathrm{g}$ for Day 15 , and $0.541 \mu \mathrm{g} / \mathrm{g}$ for Day 30. The mean concentrations of $\mathrm{Cu}$ in the plasma were <MDL for Days 15 and 30. No differences were detected between sexes or among doses for Day 0 (Table 14). Data for Day 0 are considered to be baseline.

Mean concentrations of $\mathrm{Cu}$ in blood cells on Days 0,15 , and 30 were not different between sexes. With sexes combined, no changes were found in concentrations of $\mathrm{Cu}$ in the cells from Day 0 to Day 15 to Day 30. With days combined, we detected no differences in the mean concentrations of $\mathrm{Cu}$ in blood cells among doses (Table 15).
Mean concentrations of $\mathrm{P}$ in the plasma did not differ by sex or among doses for Days 0, 15, and 30 (Table 14). Mean concentrations of $P$ in the plasma did increase from Day 0 to Day 15 to Day 30.

Mean concentrations of $\mathrm{P}$ in blood cells did not differ by sex or among doses. Within sexes and doses combined, the mean concentrations of $P$ in cells did not change from Day 0 to Day 15 to Day 30 (Table 15).

Concentrations of $\mathrm{Fe}$ in the plasma did not differ between sexes or among doses (Table 14); however, with sexes and doses combined, Fe in the plasma declined from Day 0 to Day 15 to Day 30. This decline probably resulted from switching on Day 0 from a diet of duck pellets to corn, which is low in Fe.

No differences existed between sexes from Day 0 to Day 15 to Day 30 for mean concentrations of Fe in blood cells (Table 15). With sexes combined, no differences were found in mean concentrations of $\mathrm{Fe}$ in blood cells among doses on Day 0 , Day 15, or Day 30.

Females had higher mean concentrations of $\mathrm{Ca}$ in plasma than males (Table 14). Within each sex, differences among doses did not exist in the mean concentrations of $\mathrm{Ca}$ in the plasma. However, mean concentrations of $\mathrm{Ca}$ in plasma increased from Day 0 to Day 15 to Day 30 in both sexes within each dose.

Mean concentrations of $\mathrm{Ca}$ in the blood cells were not different between sexes or among doses. The amount of $\mathrm{Ca}$, however, did change over time and an interaction was detected between sex and dose. Ca in cells increased more consistently and in larger amounts from Day 0 to Day 15 to Day 30 in females than in males.

Females had higher mean concentrations of $\mathrm{Mg}$ in the plasma than males. Within sexes, no differences were detected among doses in the mean concentrations of $\mathrm{Mg}$ in the plasma, but $\mathrm{Mg}$ increased over time in ducks within each dose.

In contrast to plasma, mean concentrations of $\mathrm{Mg}$ in red blood cells of males were higher than those of females (Table 15). No differences in the concentrations of $\mathrm{Mg}$ in blood cells were detected, and no changes from Day 0 to Day 15 to Day 30 were noted among doses.

The MDLs for $\mathrm{Zn}$ in plasma were $3.57 \mu \mathrm{g} / \mathrm{g}$ for Day $0,4.87 \mu \mathrm{g} / \mathrm{g}$ for Day 15 , and $0.613 \mu \mathrm{g} / \mathrm{g}$ for Day 30 (Table 14). The mean concentrations were $>$ MDL only for Day 30, the only data included in this report. Females had higher mean concentrations of $\mathrm{Zn}$ in their plasma than males (Table 14). 


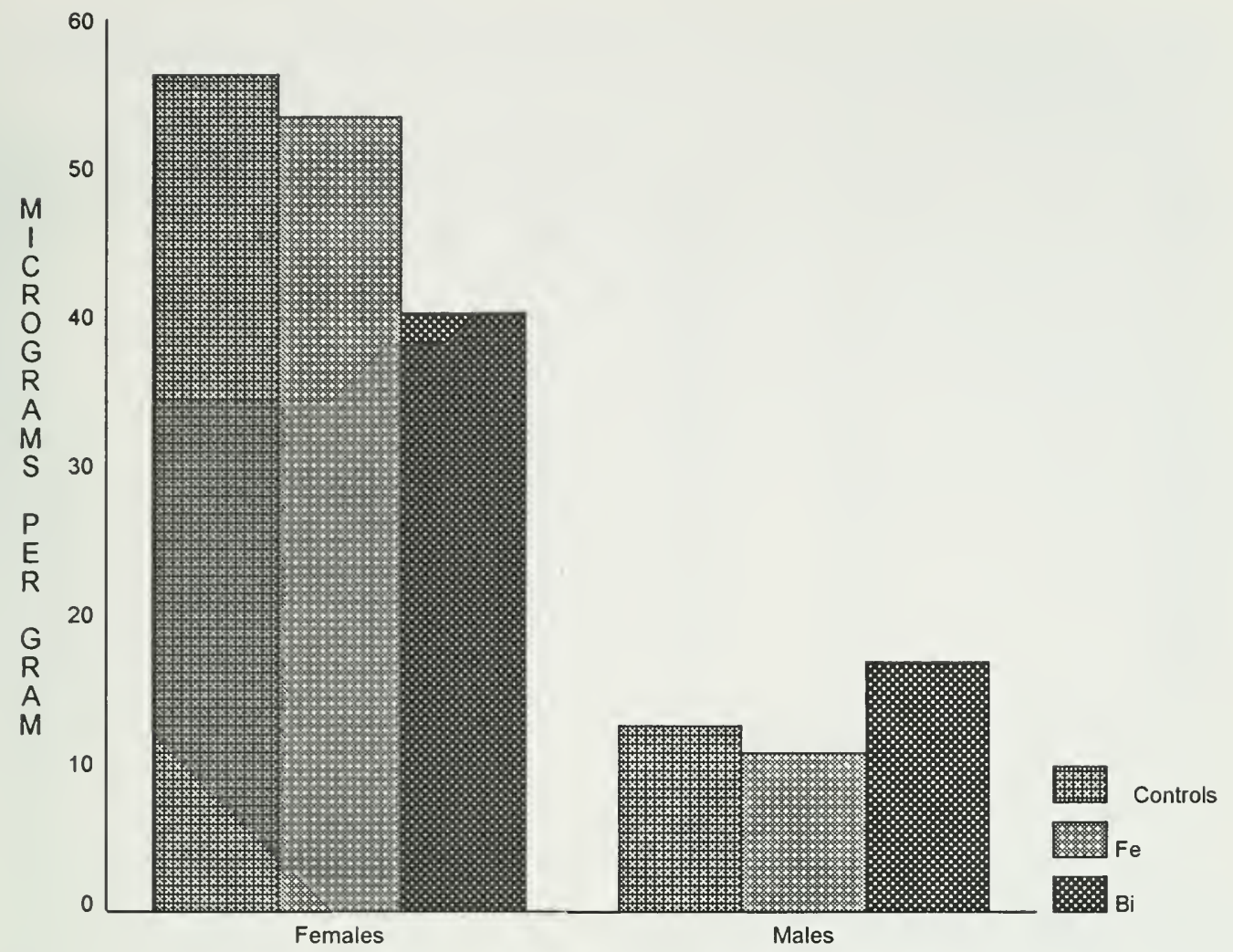

Figure 2. Mean concentrations of iron ( $\mu \mathrm{g} / \mathrm{g}$ wet weight) in gonads of game-farm mallards 30 days after dosing with $0 ; 6$, No. 4, steel (iron); or 6, No. 4, bismuth shot.

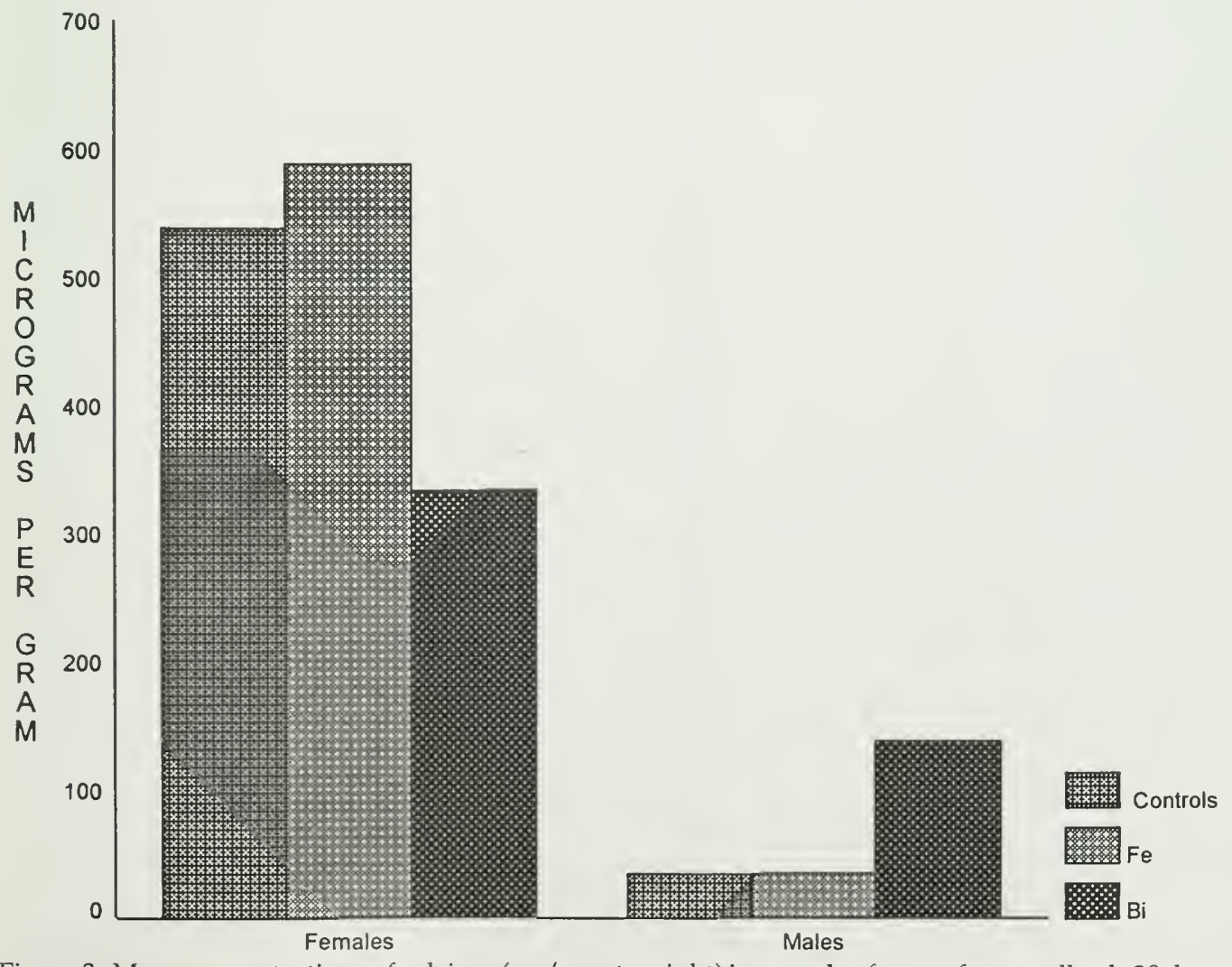

Figure 3 . Mean concentrations of calcium ( $\mu \mathrm{g} / \mathrm{g}$ wet weight) in gonads of game-farm mallards 30 days 
Table 14. Mean concentrations ( $\mu \mathrm{g} / \mathrm{g}$ wet wt) of $\mathrm{Cu}, \mathrm{P}, \mathrm{Fe}, \mathrm{Ca}, \mathrm{Mg}$, and $\mathrm{Zn}$ in plasma of game-farm mallards dosed with 0 shot (controls) compared with ducks dosed with six, No. 4, Fe shot or six, No. 4, Bi shot $(\mathrm{N}=18,19$, or 20 for each sex $)$.

\begin{tabular}{|c|c|c|c|c|c|}
\hline \multirow[b]{2}{*}{ Sex } & \multirow[b]{2}{*}{ Day } & \multirow{2}{*}{$\begin{array}{l}\text { Elements } \\
\text { Detected }\end{array}$} & \multicolumn{3}{|c|}{ Dose } \\
\hline & & & 0 & $\mathrm{Fe}$ & $\mathrm{Bi}$ \\
\hline \multirow[t]{2}{*}{ F\&M } & 0 & $\mathrm{Cu}$ & 0.334 & 0.304 & 0.370 \\
\hline & & & $0.036^{\mathrm{a}}$ & 0.031 & 0.048 \\
\hline \multirow[t]{6}{*}{$\mathrm{F}$} & 0 & $\mathrm{P}$ & 179 & 204 & 196 \\
\hline & & & 18.0 & 20.9 & 13.9 \\
\hline & 15 & & 245 & 268 & 225 \\
\hline & & & 14.1 & 12.5 & 8.2 \\
\hline & 30 & & 291 & 303 & 270 \\
\hline & & & 20.4 & 14.3 & 13.3 \\
\hline \multirow[t]{6}{*}{ M } & 0 & & 220 & 202 & 215 \\
\hline & & & 19.4 & 11.8 & 17.0 \\
\hline & 15 & & 257 & 262 & 282 \\
\hline & & & 15.2 & 6.3 & 22.3 \\
\hline & 30 & & 259 & 252 & 251 \\
\hline & & & 9.6 & 7.3 & 14.0 \\
\hline \multirow[t]{6}{*}{$\mathrm{F} \& \mathrm{M}$} & 0 & & 199 & 203 & 206 \\
\hline & & & 13.5 & 11.8 & 11.0 \\
\hline & 15 & & 251 & 265 & 252 \\
\hline & & & 10.2 & 6.9 & 12.4 \\
\hline & 30 & & 275 & 277 & 260 \\
\hline & & & 11.5 & 9.0 & 9.8 \\
\hline \multirow[t]{6}{*}{$\mathrm{F}$} & 0 & $\mathrm{Fe}$ & 8.40 & 14.5 & 10.7 \\
\hline & & & 1.2 & 3.5 & 1.7 \\
\hline & 15 & & 6.31 & 7.55 & 5.08 \\
\hline & & & 0.8 & 0.6 & 0.8 \\
\hline & 30 & & 7.47 & 9.07 & 6.85 \\
\hline & & & 0.9 & 1.0 & 0.7 \\
\hline \multirow[t]{6}{*}{$\mathrm{M}$} & 0 & & 15.4 & 7.62 & 13.8 \\
\hline & & & 4.5 & 1.0 & 3.4 \\
\hline & 15 & & 5.94 & 5.67 & 8.19 \\
\hline & & & 0.8 & 0.5 & 1.2 \\
\hline & 30 & & 7.71 & 6.08 & 5.17 \\
\hline & & & 1.1 & 0.6 & 0.5 \\
\hline \multirow[t]{6}{*}{$F \& M$} & 0 & & 11.8 & 11.1 & 12.2 \\
\hline & & & 2.3 & 1.9 & 1.9 \\
\hline & 15 & & 6.14 & 6.61 & 6.59 \\
\hline & & & 0.5 & 0.4 & 0.7 \\
\hline & 30 & & 7.48 & 7.58 & 6.03 \\
\hline & & & 0.7 & 0.7 & 0.4 \\
\hline \multirow[t]{6}{*}{$\mathrm{F}$} & 0 & $\mathrm{Ca}$ & 88.3 & 87.9 & 87.0 \\
\hline & & & 6.1 & 5.7 & 5.8 \\
\hline & 15 & & 144 & 140 & 120 \\
\hline & & & 12.2 & 7.8 & 3.8 \\
\hline & 30 & & 176 & 169 & 168 \\
\hline & & & 17.3 & 12.6 & 12.4 \\
\hline \multirow[t]{6}{*}{ M } & 0 & & 83.0 & 80.1 & 80.4 \\
\hline & & & 6.3 & 5.8 & 6.2 \\
\hline & 15 & & 110 & 117 & 115 \\
\hline & & & 5.4 & 1.7 & 1.5 \\
\hline & 30 & & 107 & 111 & 109 \\
\hline & & & 1.7 & 1.3 & 0.5 \\
\hline \multirow[t]{6}{*}{$F \& M$} & 0 & & 85.7 & 84.0 & 84.1 \\
\hline & & & 3.9 & 4.0 & 4.2 \\
\hline & 15 & & 127 & 129 & 118 \\
\hline & & & 7.2 & 4.3 & 2.1 \\
\hline & 30 & & 141 & 140 & 139 \\
\hline & & & 10.2 & 7.8 & 8.2 \\
\hline \multirow[t]{5}{*}{$\mathrm{F}$} & 0 & $\mathrm{Mg}$ & 17.4 & 19.2 & 17.8 \\
\hline & & & 1.2 & 1.4 & 1.2 \\
\hline & 15 & & 23.3 & 24.5 & 21.7 \\
\hline & & & 1.0 & 0.8 & 0.5 \\
\hline & 30 & & 26.6 & 27.0 & 26.2 \\
\hline
\end{tabular}


Table 14 continued

\begin{tabular}{cccccl}
\hline & & Elements & & Dose & \\
\cline { 3 - 5 } Sex & Day & Detected & 0 & Fe & Bi \\
\hline M & 0 & & 18.0 & 16.3 & 17.1 \\
& & & 1.5 & 1.1 & 1.3 \\
& 15 & & 22.5 & 22.7 & 23.8 \\
& & & 1.2 & 0.5 & 1.0 \\
& 30 & & 24.4 & 24.3 & 24.4 \\
& & & 0.4 & 0.4 & 0.6 \\
F \& M & 0 & & 17.7 & 17.8 & 17.5 \\
& & & 0.8 & 0.9 & 0.9 \\
& 15 & & 0.82 .8 & 23.6 & 22.6 \\
& & & 25.5 & 0.5 & 0.6 \\
& 30 & & 0.6 & 25.7 & 25.3 \\
& & & 4.56 & 0.6 & 0.5 \\
F & 30 & Zn & 0.39 & 4.27 & 4.63 \\
& & & 2.83 & 0.34 & 0.30 \\
M & 30 & & 0.13 & 2.77 & 2.72 \\
& & & 3.69 & 0.08 & 0.17 \\
F \& M & 30 & & 0.25 & 3.52 & 3.64 \\
& & & & 0.21 & 0.23 \\
\hline
\end{tabular}

a SE.

$\mathrm{Cu}$
Difference among doses; Day 0:

$$
F_{2,112}=0.74: P=0.4789 \text {. }
$$

Mean concentrations for Days 15 and 30 were <MDLs: $0.483 \mu \mathrm{g} / \mathrm{g}$ and $0.541 \mu \mathrm{g} / \mathrm{g}$, respectively. Data for Day 0 are recorded as baseline information. $P$

Difference among doses:

Change over time:

Interaction between sex and time:

$\mathrm{Fe}$

Difference among doses:

Interaction between sex and dose: $\mathrm{Ca}$

Change over time:

Difference between sexes:

Difference among doses:

Change over time:

Interaction between sex and time: $\mathrm{Mg}$

Difference between sexes:

Difference among doses:

Change over time:

$\mathrm{Zn}$

Difference between sexes; Day 30: $\quad F_{1,114}=63.84 ; P<0.00001$.

Difference among doses; Day 30: $\quad F_{1,114}=0.23 ; P=0.7928$.
$F_{2,111}=0.39: P=0.6747$.

$F_{2,222}=42.24: P<0.00001$.

$F_{2,222}=8.07 ; P=0.0005$.

$F_{2,110}=0.03 ; P=0.9747$.

$F_{2,110}=4.98 ; P=0.0085$.

$F_{2,220}=16.23 ; P<0.00001$.

$F_{1,111}=50.56 ; P=0.00001$.

$F_{2,111}=0.56 ; P=0.5712$.

$F_{2,222}=87.32 ; P<0.00001$.

$F_{2,222}=22.08 ; P<0.00001$.

$F_{1,111}=4.40 ; P=0.0383$

$F_{2,111}=0.43 ; P=0.6489$.

$F_{2,222}=102.43 ; P=0.00001$.

Means for Days 0 and 14 were <MDLs: $3.57 \mu \mathrm{g} / \mathrm{g}$ and $41.87 \mu \mathrm{g} / \mathrm{g}$, respectively. 


\section{continued from page 204}

Within sexes, no differences were found among doses in the mean concentrations of $\mathrm{Zn}$ in the plasma. We found no differences between sexes, among doses, or over time in the mean concentrations of $\mathrm{Zn}$ in blood cells.

\section{Feces}

All concentrations of $\mathrm{Bi}$ in the feces were $<\mathrm{MDL}$ $(103 \mu \mathrm{g} / \mathrm{g}$, dry wt) on Day 0. We found little change in the concentrations of $\mathrm{Bi}$ in the feces of 0 dosed and Fe-dosed ducks from Day 1 to Day 2. We did not perform statistical tests because most concentrations were $<\mathrm{MDL}$. For Bi-dosed ducks, $B i$ in the feces increased from $<$ MDL on Day 0 to $2,275 \mu \mathrm{g} / \mathrm{g}$ on Day 1 to $3,689 \mu \mathrm{g} / \mathrm{g}$ on Day 2 . These high concentrations were maintained to the end of the 30-day study-3,636 $\mu \mathrm{g} / \mathrm{g}$ for Days $1-10$ combined and $3,485 \mu \mathrm{g} / \mathrm{g}$ for Days $11-30 \mathrm{com}-$ bined (Table 16).

The main purpose of collecting and analyzing the feces was to provide data for calculating the percentage of dissolved $\mathrm{Bi}$ (from Bi shot in the gizzard) that was excreted in the feces. An estimated $90 \%$ of all fecal matter was analyzed. The remaining $10 \%$ fell on the ground under the pens, adhered to the pans when feces were collected, was blown out of the pans by high winds accompanied by rain, or adhered to the plastic bags when the samples were removed for weighing and analysis. The Bi in the estimated $10 \%$ of the feces lost was included in our estimates of the percentage of Bi excreted.

All fecal samples that were analyzed were dried to constant weight and then weighed. By using the concentration of $\mathrm{Bi}$ in each sampledaily concentrations for Days 1-10 and one concentration for the combined sample for Days 1130 -the amount of Bi excreted in the feces was calculated for each Bi-dosed duck. The results were compared with the amount of Bi dissolved from the six Bi shot dosed in the same duck. By this process, we estimated a mean of $88 \%$ of the $\mathrm{Bi}$ dissolved from the shot in the gizzards was excreted in the feces. The percentages ranged from $61 \%$ to $103 \%$ in the 10 ducks.

$\mathrm{Sn}$ in the feces of all ducks was <MDL (19.5 $\mu \mathrm{g} / \mathrm{g}$, dry wt) on Day 0 and remained below the MDL for Day 1 and Day 2 in 0-dosed and Fe-dosed ducks. In the Bi-dosed ducks, mean concentrations of Sn increased to $185 \mu \mathrm{g} / \mathrm{g}$ on Day 1, was $111 \mu \mathrm{g} / \mathrm{g}$ on Day 2, and declined to $67 \mu \mathrm{g} / \mathrm{g}$ for Days 11-30 combined (Table 16).

Sn made up only $2 \%$ of the dosed Bi shot compared with $98 \%$ for Bi. In the feces analyzed from 10 Bi-dosed ducks, Sn increased from $<$ MDL $(19.5 \mu \mathrm{g} / \mathrm{g}$, dry wt) on Day 0 to a range of 48 to 321 $\mu \mathrm{g} / \mathrm{g}$ on Day 1 . By making calculations similar to those described for $\mathrm{Bi}$, we estimated that a mean of $85 \%$ of the $\mathrm{Sn}$ dissolved from the Bi shot was excreted in the feces. The calculated percentages of $\mathrm{Sn}$ dissolved from the shot that were excreted in the feces of each of the 10 ducks ranged from 58 to $127 \%$.

The mean concentrations of Fe in the feces of 0 -dosed ducks declined from $1174 \mu \mathrm{g} / \mathrm{g}$ on Day 0 to $809 \mu \mathrm{g} / \mathrm{g}$ on Day 1 to $358 \mu \mathrm{g} / \mathrm{g}$ on Day 2, but increased to $520 \mu \mathrm{g} / \mathrm{g}$ for Days 11-30 combined. The mean concentrations of $\mathrm{Fe}$ in feces of Fedosed ducks increased from $1055 \mu \mathrm{g} / \mathrm{g}$ on Day 0 to $2442 \mu \mathrm{g} / \mathrm{g}$ on Day 1 to $2611 \mathrm{mg} / \mathrm{g}$ on Day 2. In Bi-dosed ducks, the mean concentrations of $\mathrm{Fe}$ decreased from $1,010 \mu \mathrm{g} / \mathrm{g}$ on Day 0 to $720 \mu \mathrm{g} / \mathrm{g}$ on Day 1 to $514 \mu \mathrm{g} / \mathrm{g}$ on Day 2 to $349 \mu \mathrm{g} / \mathrm{g}$ for Days 11-30. Although Bi-dosed ducks were associated with temporal decreases of Fe in the feces, a similar relationship was evident for 0 -dosed ducks. We assumed that the sharp declines in the amount of $\mathrm{Fe}$ in the feces over time were a result of the switch in diets on Day 0 from commercial duck pellets to corn, which is known to be low in Fe.

\section{Histopathology}

Lesions were identified in the testes, ovaries, kidneys, and livers in control and dosed ducks, but presence of a specific lesion and dosage were not correlated. The mild inflammatory changes seen histologically were within the range of normal tissues of birds.

\section{Gonadal Lesions}

\section{Female}

Tissue sections of many of the females documented a mild to moderate lymphocytic oophoritis, but without any evidence of etiology. This lesion typically consisted of scattered lymphocytes and plasma cells in the interstitium of the ovary. Severe necrotizing oophoritis was observed in the ovary of one 0 -dosed female, which is consistent with an egg yolk peritonitis. Milder lesions with necrotic areas were detected in two other $\mathrm{Bi}$-dosed females. These lesions may represent resolving cases of egg yolk peritonitis. Weights of ovaries ranged widely.

\section{Male}

No inflammatory lesions were detected in gonads of male ducks except for one Fe-dosed duck 
Table 15. Mean concentrations ( $\mu \mathrm{g} / \mathrm{g}$ wet wt) of $\mathrm{Cu}, \mathrm{P}, \mathrm{Fe}, \mathrm{Ca}, \mathrm{Mg}$, and $\mathrm{Zn}$ in red blood cells of game-farm mallards dosed with 0 shot (controls) compared with ducks with six, No. 4, Fe shot or six, No. 4 Bi, shot ( $N=18,19$, or 20 for each sex).

\begin{tabular}{|c|c|c|c|c|c|}
\hline \multirow[b]{2}{*}{ Sex } & \multirow[b]{2}{*}{ Day } & \multirow{2}{*}{$\begin{array}{l}\text { Elements } \\
\text { Detected }\end{array}$} & \multicolumn{3}{|c|}{ Dose } \\
\hline & & & 0 & $\mathrm{Fe}$ & $\mathrm{Bi}$ \\
\hline \multirow[t]{6}{*}{$\mathrm{F}$} & 0 & $\mathrm{Cu}$ & 0.612 & 0.557 & 0.681 \\
\hline & & & $0.076^{\mathrm{a}}$ & 0.034 & 0.099 \\
\hline & 15 & & 0.709 & 0.668 & 0.624 \\
\hline & & & 0.073 & 0.042 & 0.095 \\
\hline & 30 & & 0.626 & 0.688 & 0.699 \\
\hline & & & 0.094 & 0.128 & 0.039 \\
\hline \multirow[t]{6}{*}{$\mathrm{M}$} & 0 & & 0.762 & 0.956 & 0.605 \\
\hline & & & 0.192 & 0.456 & 0.107 \\
\hline & 15 & & 0.539 & 0.590 & 0.645 \\
\hline & & & 0.072 & 0.159 & 0.120 \\
\hline & 30 & & 0.675 & 0.626 & 0.577 \\
\hline & & & 0.118 & 0.148 & 0.081 \\
\hline \multirow[t]{6}{*}{$\mathrm{F} \& \mathrm{M}$} & 0 & & 0.687 & 0.757 & 0.644 \\
\hline & & & 0.103 & 0.288 & 0.072 \\
\hline & 15 & & 0.624 & 0.629 & 0.630 \\
\hline & & & 0.053 & 0.081 & 0.075 \\
\hline & 30 & & 0.651 & 0.657 & 0.643 \\
\hline & & & 0.074 & 0.097 & 0.045 \\
\hline \multirow[t]{6}{*}{$\mathrm{F}$} & 0 & $\mathrm{P}$ & 2544 & 2311 & 2303 \\
\hline & & & 240 & 41 & 70 \\
\hline & 15 & & 2369 & 2395 & 2343 \\
\hline & & & 56 & 72 & 48 \\
\hline & 30 & & 2305 & 2212 & 2385 \\
\hline & & & 55 & 101 & 40 \\
\hline \multirow[t]{6}{*}{ M } & 0 & & 2336 & 2359 & 2452 \\
\hline & & & 42 & 49 & 133 \\
\hline & 15 & & 2445 & 2396 & 2282 \\
\hline & & & 44 & 36 & 77 \\
\hline & 30 & & 2605 & 2556 & 2555 \\
\hline & & & 276 & 134 & 160 \\
\hline \multirow[t]{6}{*}{$\mathrm{F} \& \mathrm{M}$} & 0 & $\mathrm{P}$ & 2440 & 2335 & 2376 \\
\hline & & & 121 & 32 & 74 \\
\hline & 15 & & 2407 & 2395 & 2322 \\
\hline & & & 36 & 40 & 45 \\
\hline & 30 & & 2455 & 2384 & 2463 \\
\hline & & & 141 & 87 & 82 \\
\hline \multirow[t]{6}{*}{$\mathrm{F}$} & 0 & $\mathrm{Fe}$ & 804 & 727 & 739 \\
\hline & & & 82.0 & 13.4 & 21.9 \\
\hline & 15 & & 769 & 789 & 776 \\
\hline & & & 18.2 & 25.3 & 19.1 \\
\hline & 30 & & 732 & 705 & 762 \\
\hline & & & 19.5 & 31.9 & 13.1 \\
\hline \multirow[t]{6}{*}{ M } & 0 & & 758 & 752 & 776 \\
\hline & & & 16.4 & 19.5 & 49.6 \\
\hline & 15 & & 803 & 787 & 747 \\
\hline & & & 14.3 & 14.3 & 26.3 \\
\hline & 30 & & 832 & 805 & 831 \\
\hline & & & 97.8 & 33.7 & 45.3 \\
\hline \multirow[t]{6}{*}{$F \& M$} & 0 & $\mathrm{Fe}$ & 781 & 739 & 757 \\
\hline & & & 41.4 & 11.8 & 26.5 \\
\hline & 15 & & 786 & 788 & 761 \\
\hline & & & 11.8 & 14.3 & 16.2 \\
\hline & 30 & & 782 & 755 & 794 \\
\hline & & & 49.8 & 24.3 & 23.8 \\
\hline \multirow[t]{3}{*}{$\mathrm{F}$} & 0 & $\mathrm{Ca}$ & 32.0 & 31.0 & 29.3 \\
\hline & & & 1.4 & 1.8 & 1.4 \\
\hline & 15 & & 42.1 & 33.2 & 32.8 \\
\hline
\end{tabular}

Table 15 continued on page 210 
Table 15 continued

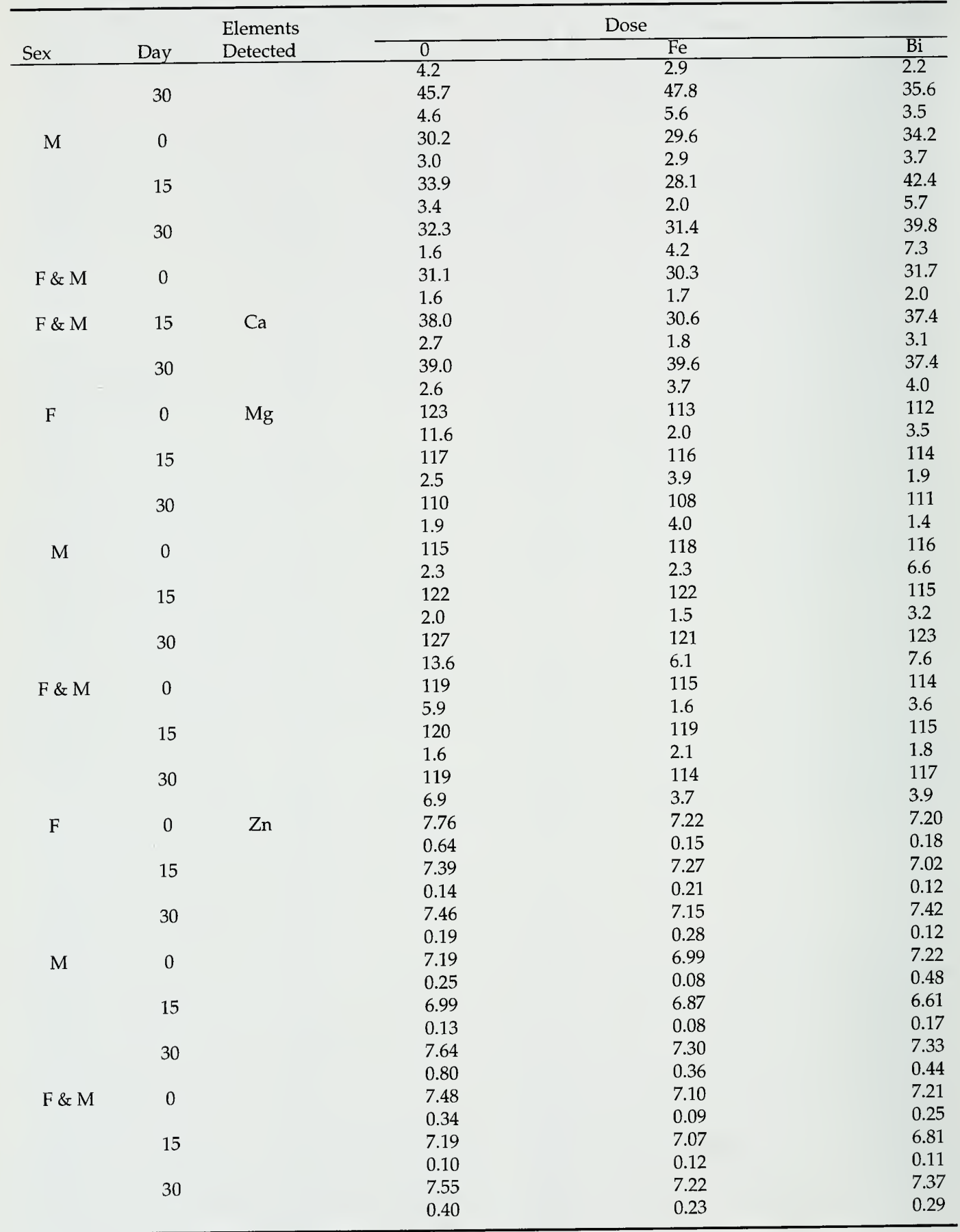

a SE.

$\mathrm{Cu}$

Difference among doses:

$P$

Difference among doses: Fe

Difference among doses: $\mathrm{Ca}$

Difference among doses:
$F_{2,113}=0.11 ; P=0.8938$.

$F_{2,113}=0.47 ; P=0.6293$.

$F_{2,13}=0.48 ; P=0.6193$.

$F_{2,113}=0.64 ; p=0.5306$.
Interaction between sex and dose: $F_{2113}=5.49 ; P=0.0053$.

Change over time:

$\mathrm{Mg}$

Difference between sexes: $\quad F_{1,113}=5.85 ; P=0.0171$.

Difference among doses: $\quad F_{2,113}=0.85 ; P=0.4282$.

$\mathrm{Zn}$

Difference among doses: $\quad F_{2,113}=1.18 ; P=0.3115$. 
Table 16. Mean concentrations ( $\mu \mathrm{g} / \mathrm{g}$ dry wt) of $\mathrm{Bi}, \mathrm{Sn}$, and Fe in feces of game-farm mallards (sexes combined) dosed with 0 shot (controls) compared with ducks dosed with six, No. 4, Fe shot or six, No. 4, Bi shot.

\begin{tabular}{|c|c|c|c|c|}
\hline \multirow{2}{*}{$\begin{array}{l}\text { Elements } \\
\text { Detected }\end{array}$} & \multirow[b]{2}{*}{ Days $^{a}$} & \multicolumn{3}{|c|}{ Dose } \\
\hline & & 0 & $\mathrm{Fe}$ & $\mathrm{Bi}$ \\
\hline \multirow[t]{9}{*}{$\overline{\mathrm{Bi}}$} & 0 & $<\mathrm{MDL}^{\mathrm{b}}$ & $<\mathrm{MDL}^{\mathrm{c}}$ & $<\mathrm{MDL}^{\mathrm{d}}$ \\
\hline & 1 & $<\mathrm{MDL}^{\mathrm{b}}$ & $<\mathrm{MDL}^{\mathrm{b}}$ & $2275^{e}$ \\
\hline & & & & $414^{f}$ \\
\hline & 2 & $<\mathrm{MDL}^{\mathrm{b}}$ & $<\mathrm{MDL}^{\mathrm{c}}$ & $3689^{e}$ \\
\hline & & & & 588 \\
\hline & $1-10$ & $<\mathrm{MDL}^{\mathrm{b}}$ & $<\mathrm{MDL}^{\mathrm{a}}$ & $3636^{g}$ \\
\hline & & & & 183 \\
\hline & $11-30$ & $<\mathrm{MDL}^{\mathrm{a}}$ & $<\mathrm{MDL}^{\mathrm{a}}$ & $3485^{g}$ \\
\hline & & & & 382 \\
\hline \multirow[t]{7}{*}{ Sn } & 0 & $<\mathrm{MDL}^{\mathrm{b}}$ & $<\mathrm{MDL}^{\mathrm{c}}$ & $<\mathrm{MDL}^{\mathrm{d}}$ \\
\hline & 1 & $<\mathrm{MDL}^{\mathrm{b}}$ & $<\mathrm{MDL}^{\mathrm{b}}$ & $185^{e}$ \\
\hline & & & & 29.2 \\
\hline & 2 & $<\mathrm{MDL}^{\mathrm{b}}$ & $<\mathrm{MDL}^{\mathrm{c}}$ & $111^{e}$ \\
\hline & & & & 23.9 \\
\hline & $11-30$ & $<\mathrm{MDL}^{\mathrm{b}}$ & $<\mathrm{MDL}^{\mathrm{b}}$ & $67^{e}$ \\
\hline & & & & 5.7 \\
\hline \multirow[t]{8}{*}{$\mathrm{Fe}$} & 0 & $1174^{\mathrm{b}}$ & $1055^{c}$ & $1010^{e}$ \\
\hline & & 174 & 38 & 38 \\
\hline & 1 & $809^{b}$ & $2242^{b}$ & $720^{e}$ \\
\hline & & 18.2 & 409 & 70.6 \\
\hline & 2 & $358^{\mathrm{b}}$ & $2611^{c}$ & $514^{e}$ \\
\hline & & 21.4 & 563 & 66.6 \\
\hline & $11-30$ & $520^{\mathrm{b}}$ & $2288^{b}$ & $349 \mathrm{~g}$ \\
\hline & & 76.5 & 410 & 23.0 \\
\hline
\end{tabular}

ays after dosing; $0=$ day of dosing.

b $\mathrm{N}=3$.

d $\mathrm{N}=5$.

$\mathrm{N}=4$.

e $\mathrm{N}=10$.

f $\mathrm{SE}$.

g $\mathrm{N}=9$.

MDL $=$ Method Detection Limit by ICP:

MDL for $\mathrm{Bi}=103 \mu \mathrm{g} / \mathrm{g}$ (dry wt) for Days $0,1,2$, and $1-10$ and $58.9 \mu \mathrm{g} / \mathrm{g}$ for Days 11-30.

MDL for $\mathrm{Sn}=19.5 \mu \mathrm{g} / \mathrm{g}$ (dry wt) for Days 0,1 , and 2 and $14.9 \mu \mathrm{g} / \mathrm{g}$ for Days 11-30.

MDL for Fe $=31.8 \mu \mathrm{g} / \mathrm{g}$ (dry wt) for Days 0,1 , and 2 and $19.2 \mu \mathrm{g} / \mathrm{g}$ for Days 11-30.

continued from page 208

and one Bi-dosed duck. In the Fe-dosed duck, a small-sperm granuloma was found, but the residual parenchyma was normal. The Fe-dosed duck had evidence of a locally extensive tubular atrophy consisting of a decreased height in the seminiferous epithelium in one zone of the examined testis. The adjacent tubules were within normal limits with no evidence of inflammation.

The testis of the Bi-dosed duck contained scattered aggregates of lymphocytes and plasma cells, and multinucleated giant cells (presumably sloughed spermatocytes) were observed within scattered tubules. Evidence of normal production of spermatozoa was present on the slide.

Asmall percentage of ducks in all threegroups had mild vacuolar changes in the seminiferous epithelium. These ducks had spermatozoa within the genital ducts and in seminiferous epithelium.
Liver

Nearly all ducks had a variable number of lymphocytes and plasma cells within the liver. The most common pattern was around the portal triads. Occasionally, the inflammatory cells formed small nodules scattered in the parenchyma. One 0 -dosed male had abscesses within the liver, which probably represented an acute bacterial infection. The hepatic lipidosis seen histologically seemed to correlate with livers that were heavier.

\section{Kidneys}

Nearly all ducks had a variable number of lymphocytes and plasma cells in the wall of the ureter.

\section{Gizzard}

On Day 30, the contents of the gizzards from all 120 ducks were removed and saved, and those from Fe-dosed and Bi-dosed ducks were exam- 
ined for retained shot. The linings of all gizzards appeared to be unaffected, and there was no pattern of variation among doses. No lesions were detected in any of the gizzard sections examined.

\section{Discussion}

\section{Copper}

Approximately twice the concentration of $\mathrm{Cu}$ was detected in the livers of male ducks as in the livers of female ducks in all dosed groups (Table 11). Hanson and Jones (1974) found significantly higher concentrations of $\mathrm{Cu}$ in the feathers of female Ross' geese (Anser rossii) than in males. They presumed estrogen was responsible for the difference. Underwood (1971:61, 63), discussing $\mathrm{Cu}$ in the liver, stated, "There is no effect of sex, except in the Australian salmon (Arripis trutta) in which the female carried higher concentrations than the male."

Van Campen (1971:214) reported that "Administration of estrogens induces large increases in serum copper in humans, rats, and swine." $\mathrm{He}$ also reported that androgens increased serum $\mathrm{Cu}$ concentrations in humans. Hill and Matrone (1961) found that when both $\mathrm{Cu}$ and Fe were low in the diet, an increase in one partly compensated for the deficiency of the other. Matrone (1960) concluded that $\mathrm{Cu}$ absorption is not directly affected by Fe. Thus, the Fe:Cu interaction is affected by something other than absorption. In the present study, the diet (corn) of the ducks (both females and males) was low in $\mathrm{Fe}$, but dosing with Fe shot did not have a significant effect on the level of $\mathrm{Cu}$ in the livers.

Van Campen (1971:221-222) stated, "The factors that are most influential in determining the tissue levels of copper are age, hormones, disease and diet. . . calcium apparently can either increase or decrease copper absorption, depending on the composition of the diet to which they are added."

In our study, females had higher mean concentrations of $\mathrm{Cu}$ in their gonads than males, which is in contrast to kidneys and livers where males always had higher mean concentrations of $\mathrm{Cu}$.

\section{Phosphorous}

The lower concentrations of $\mathrm{P}$ in livers of $\mathrm{Fe}$ dosed males, as compared with females, resulted from decreases of $\mathrm{P}$ in the livers of $\mathrm{Fe}$-dosed males. Concentrations of $\mathrm{P}$ were only slightly higher in the livers of Fe-dosed females than in 0- dosed females. Dosing with Bi shot also caused a decrease in the concentration of $\mathrm{P}$ in livers of males, which resulted in a significant difference between the sexes. Concentrations of $\mathrm{P}$ were essentially the same in 0-dosed females and $\mathrm{Bi}$ dosed females (Table 11).

\section{Iron}

Dosing with Fe shot resulted in large concentrations of Fe deposits in the livers, but dosing with Bi shot did not significantly affect the concentrations of Fe in the liver (Table 11). Although females dissolved a higher percentage of the dosed Fe shot than males (Table 1), the Fe-dosed females did not have significantly higher concentrations of $\mathrm{Fe}$ in their livers than the Fe-dosed males.

Females had significantly higher concentrations of Fe in their gonads than males. These sex differences in the concentrations of Fe in the gonads may be related to the preparation of the ovaries for egg laying. No differences were found in the mean concentrations of $\mathrm{Fe}$ in the gonads attributed to dosing with either Fe shot or Bi shot.

\section{Calcium}

It appears that dosing with Fe or Bi shot is associated with lower concentrations of $\mathrm{Ca}$ in the livers and kidneys of ducks as compared with controls (Table 9).

Forth and Rummel (1971:182) reported that increases in $\mathrm{Fe}$ or $\mathrm{Ca}$ mutually inhibited each other in their transfer through the small intestine of the rat. They concluded that it was possible there is ". . a common transport mechanism for iron and calcium ...." Perhaps Bi induces a similar reduction in the transfer of $\mathrm{Ca}$, although $\mathrm{Bi}$ has apparently not been studied in this context.

Ca increased substantially in the plasma of both males and females for all dosed groups from Day 0 to Day 15 to Day 30 (Table 14). The increase cannot be related to increase in $\mathrm{Ca}$ in the diet because after dosing all ducks were on a corn diet, and corn is low in Ca. Ca in the plasma among doses did not vary statistically.

\section{Feces}

Both $\mathrm{Bi}$ and $\mathrm{Sn}$ greatly increased in the feces of $\mathrm{Bi}-$ dosed ducks the day after dosing. Birds excreted $\mathrm{Bi}$ in the feces at high concentrations to the end of the 30-day study. Mean concentrations of Bi were not substantially different between 0 -dosed and Fe-dosed ducks on Days 0,1, and 2. Bi was much higher in feces of Bi-dosed ducks than in either 0dosed or Fe-dosed ducks on Days 1 and 2. It appears that almost all of the Bi dissolved from $\mathrm{Bi}$ 
shot in the gizzards is excreted in the feces of ducks.

The mean concentration of $\mathrm{Sn}$ in the feces of Bi-dosed ducks was higher at the end of the 30day study than the background level found the day prior to dosing. However, the mean concentration of $\mathrm{Sn}$ in the feces of Bi-dosed ducks declined substantially after Day 10.

These findings for $\mathrm{Sn}$ in the feces seem to support Underwood (1971), who reported that the available evidence for humans shows that $\mathrm{Sn}$ is poorly absorbed, poorly retained, and excreted primarily in the feces. In humans, the amount of Sn ingested with food was approximately the same as the amount excreted in the feces. Underwood's conclusion was that Sn shows little toxicity, probably because it is absorbed slowly and is excreted rapidly in feces.

The mean concentration of $\mathrm{Fe}$ in feces declined sharply for both 0-dosed and Bi-dosed ducks starting on Day 1 . The decline continued to the end of the study in Bi-dosed ducks. Feces of 0 dosed and $\mathrm{Fe}$-dosed ducks were not analyzed for the entire study. The decline of $\mathrm{Fe}$ in feces of 0 dosed and Bi-dosed ducks was probably a result of switching on Day 0 from a diet of commercial duck food to corn, which is low in Fe.

\section{Conclusions}

We detected no toxic effects in game-farm mallards dosed with six $\mathrm{Bi} / \mathrm{Sn}$ alloy shot and observed for 30 days. Survival, body weight, Hct, and weights of organs were not affected. Gross and microscopic examination of the kidneys, liver, and gonads of the ducks also revealed only slight tissue changes. Our data support the conclusions of Sanderson et al. 1992, who reported no toxic effects in game-farm mallards dosed with $100 \% \mathrm{Bi}$ shot.

A number of differences in weights of organs and in mean concentrations of individual elements were detected between females and males. These differences appear related to physiological changes associated with the onset of breeding, especially in egg-laying females.

Although a few "anomalies" were linked to dosing with Fe shot or with Bi shot, no toxic effects were detected with either. For example, livers and kidneys of both Bi-dosed and Fe-dosed ducks had lower mean concentrations of $\mathrm{Ca}$ than livers and kidneys of 0 -dosed ducks. The difference in the mean concentrations of $\mathrm{Ca}$ in the livers of $\mathrm{Fe}$ dosed ducks versus Bi-dosed ducks was not significant (Table 11).
With two exceptions (kidneys of males, mean $=0.528 \mu \mathrm{g} / \mathrm{g}$ [range 0.36 to $0.72 \mu \mathrm{g} / \mathrm{g}$ ], and livers of males, mean $=0.246 \mu \mathrm{g} / \mathrm{g}$ [range 0.18 to 0.37 $\mu \mathrm{g} / \mathrm{g}])$, Bi was not found in the livers, kidneys, or gonads of 0 -dosed ducks. The mean concentrations of $\mathrm{Bi}$ in kidneys of $\mathrm{Bi}$-dosed ducks were 8.05 $\mu \mathrm{g} / \mathrm{g}$ for females (range 4.69 to $12.6 \mu \mathrm{g} / \mathrm{g}$ ) and $4.77 \mu \mathrm{g} / \mathrm{g}$ (range 2.02 to $8.82 \mu \mathrm{g} / \mathrm{g}$ ) for males. The mean concentration of $\mathrm{Bi}$ in livers of Bi-dosed females was $2.79 \mu \mathrm{g} / \mathrm{g}$ (range 1.19 to $5.63 \mu \mathrm{g} / \mathrm{g}$ ). The differences for $\mathrm{Bi}$-dosed versus 0 -dosed ducks were significant for both kidneys and livers. Both macro and micro histological observations detected no toxic effects of $\mathrm{Bi}$ on the kidneys, liver, or gonads. 


\section{Literature Cited}

Abbracchio, M.P., W. Balduini, A. Cavallaro, P. Adamoli, M. Fittipaldi, F. Muzio, S. Malandrino, and F. Cattabeni 1985. Brain and blood levels of bismuth after oral or parenteral administration of tripotassium-dicitrato bismuthate to rats. NeuroToxicology 6(3):139-144.

Anderson, William L. 1992. Legislation and lawsuits in the United States and their effects on nontoxic shot regulations. Pages 56-60 in D.J.Pain, ed. Proceedings of an international waterfowl and wetlands research bureau workshop, Brussels, Belgium. 1991. IWRB Special Publication 16, Slimbridge, UK.

Canadian Wildlife Service. 1995. Minister Copps acts on two toxic substances. News release dated 11 July 1995. 6 pp.

Dipalma, J.R. 1988. Bismuth toxicity. American Family Physician 78(5):244-246.

Environment Canada. 1992. Guidelines regarding the toxicity tests required for the approval of candidate non-toxic shot (to be submitted to the meeting of the executive in January 1993). Environment Canada. 9 pp.

Forth, W., and W. Rummel. 1971. Absorption of iron and chemically related metals in vitro and in vivo: specificity of the iron binding system in the mucosa of the jejunum. Pages 173-191 in S.C. Skorya and D. Waldron-Edward, eds. Intestinal absorption of metal ions, trace elements and radionuclides. Pergamon Press, Oxford, New York, Toronto, Sydney, Braunschweig. 431 pp.

Fowler, B.A., and V. Vouk. 1979. Bismuth. Pages 345-353 (Chapt. 20) in L. Friberg, G.F. Nordberg, and V. Vouk, eds. Handbook on the toxicity of metals. Elsevier/North-Holland Biomedical Medical Press, Amsterdam, New York.

Glaser, J.A., D.L. Foerst, G.D. McKee, S.A. Quave, and W.L. Budde. 1981. Trace analyses for wastewaters. Environmental and Science Technology 15(12):1426-1435.

Greenberg, A.E., L.S. Clesceri, and A.D. Eaton, eds. 1992. Standard method for the examination of water and wastewater. American Public Health Association, American Waste Water Works Association, and Water Environment Federation. 18th ed. Section 3113 Metals by electrothermal atomic absorption spectrometry: 3-20 through 3-28.

Gregus, Z., and C.D. Klaassen. 1986. Disposition of metals in rats: a comparative study of fecal, urinary, and biliary excretion and tissue distribution of eighteen metals. Toxicology and Applied Pharmacology 85:24-38.

Hamilton, E.J., M.J. Minski, and J.J. Cleary. 19721973. The concentration and distribution of some stable elements in healthy human tissues from the United Kingdom. Science of the Total Environment 1:341-374.

Hanson, H.C., and R.L. Jones. 1974. An inferred sex differential in copper metabolism in Ross' geese (Anser rossii): biogeochemical and physiological considerations. Arctic 27(2):111-120.

Hanzlik, P.J., and E. Presho 1923. Comparative toxicity of metallic lead and other heavy metals for pigeons. Journal of Pharmacology and Experimental Therapeutics 21(2):145-150.

Haseltine, S.D., and L. Sileo. 1983. Response of American black ducks to dietary uranium: a proposed substitute for lead shot. Journal of Wildlife Management 47:1124-1129.

Hill, C.H., and G. Matrone 1961. Studies on copper and iron deficiencies in growing chickens. Journal of Nutrition 73:425.

Hillemond, P., M. Palliere, B. Laquais, and P. Bauvet. 1977. Traitment bismuthique et bismuthemie. Semaine des Hopitaux de Paris 53:1663-1669.

International Commission on Radiological Protection. 1960. Report of Committee II on permissible dose for internal radiation. International Commission on Radiological Protection, Publication No. 2. Pergamon Press, Oxford 218-219.

Irby, H.D., L.N. Locke, and G.E. Bagley. 1967. Relative toxicity of lead and selected substitute shot types to game farm mallards. Journal of Wildlife Management 31:253-257.

Key, M.M., A.F.Henschel, J. Butler, R.N. Ligo, and I.R. Tabershha, eds. Lorice Ede, manuscript ed. 1977. Occupational diseases. A guide to their recognition. Bismuth and compounds. Page 338. United States Department of Health, Education, 
and Welfare, Public Health Service, Center for Disease Control, National Institutes of Occupational Safety and Health. Revised Edition.

Krigman, M.R., T.W. Bouldin, and P. Mushak. 1985. Metal toxicity in the nervous system. Monographs in Pathology 58-100.

Lee, S.P. 1981. Studies on the absorption and excretion of tripotassium dicitrate bismuthate in man. Research Communications in Chemical Pathology and Pharmacology 34:359-364.

Locke, M., H. Nichol, and C. Kotola-Pirie. 1987. Binding of bismuth to cell components: clue to mode of action and side effects. Canadian Medical Association Journal 137:991-992.

Longcore, J.R., R. Andrews, L.N. Locke, G.E. Bagley, and L.T. Young. 1974. Toxicity of lead and proposed substitute shot to mallards. U.S. Department of the Interior, Fish and Wildlife Service, Special Scientific Report-Wildlife No. 183. $23 \mathrm{pp}$.

Matrone, G. 1960. Studies on copper and iron deficiencies in growing chickens. Journal of $\mathrm{Nu}-$ trition 93:425.

Moser, M. 1992. International Lead Poisoning Newsletter. International Waterfowl and Wetlands Research Bureau, September. 1992. $17 \mathrm{pp}+$ appendices.

Oehme, F.W., ed. 1979. Pages 603-605 in Toxicity of heavy metals in the environment. Part 2. Bismuth. Marcel Dekker, Inc., New York and Basel.

Ross, J.F., Z. Sahenk, C. Hyser, J.P. Mendell, and C.L. Alden 1988. Characterization of a murine model for human bismuth encephalopathy. NeuroToxicology 9(4):581-586.

Sanderson, G.C., S.G. Wood, G.L. Foley, and J.D. Brawn 1992. Toxicity of bismuth shot compared with lead and steel shot in game-farm mallards. Transactions of the North American Wildlife and Natural Resources Conference 57:526-540.

Sanderson, G.C., W.L. Anderson, G.,L. Foley, S.P. Havera, L.M. Skowron, J.W. Brawn, G.D. Taylor, and J.W,. Seets. 1997a. Effects of lead, iron, and bismuth alloy shot embedded in the breast muscles of game-farm mallards. Journal of Wildlife Diseases. In press.
Sanderson, G.C., W.L. Anderson, G.L. Foley, K.L. Duncan, L.M. Skowron, J.D. Brawn, and J.W., Seets 1997b. Toxicity of ingested bismuth/tin alloy shot in game-farm mallards: chronic health effects and effects on reproduction. Illinois Natural History Survey Bulletn 35(4):217-252.

Serfontein, W.J., and R. Mekel. 1979. Review of bismuth blood and urine levels in patients after administration of therapeutic bismuth formulations in relation to the problem of bismuth toxicity in man. Research Communications in Chemical Pathology and Pharmacology 26:391-411.

Slikkerveer, A., and F.A. de Wolff 1989. Pharmacokinetics and toxicity of bismuth compounds. Medical Toxicology and Adverse Drug Experience 4:303-323.

Thomas, D.W., T.F. Hartley, P,. Coyle, and S. Soecki. 1988. Bismuth. Chapter 11, pages 115-127 in H.G. Seiler and H. Segil, eds. Handbook on toxicology of inorganic compounds. Marcel Dekker, Inc., New York and Basel.

Underwood, E.J. 1971. Trace elements in human and animal nutrition. 3rd Ed. Academic Press, New York and London. 543 pp.

Van Campen, D.R. 1971. Absorption of copper from the gastrointestinal tract. Pages 211-227 in S.C. Skoryon and D. Waldron-Edward, eds. Intestinal absorption of metal ions, trace elements and radionuclides. Pergamon Press, Oxford, New York, Toronto, Sydney, Braunschweig. 431 pp.

Venugopal, B., and T.D. Luckey. 1978. Chemical toxicity of metals and metalloids. Pages 215-219 and 354-401 in Metal toxicity in mammals. 2. Plenum Press, New York and London.

Woods, J.S., and B.A. Fowler 1987. Alteration of mitochondrial structure and heme biosynthetic parameters in liver and kidney cells by bismuth. Toxicology and Applied Pharmacology 90:274283. 



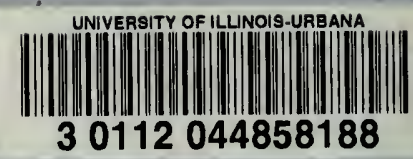

Illinois Natural History Survey

Natural Resources Building

607 East Peabody Drive

Champaign, Illinois 61820

$217=333-6880$

A Division of the Illinois Department of Natural Resources

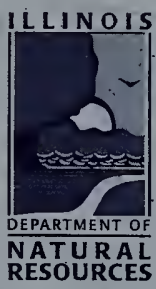

